\title{
Ballistic response of hexagonal boron nitride monolayer under impact of a nano-projectile
}

DOI:

10.1016/j.mechmat.2019.03.003

\section{Document Version}

Accepted author manuscript

Link to publication record in Manchester Research Explorer

\section{Citation for published version (APA):}

Tian, H., Zhang, B., \& Li, Q. (2019). Ballistic response of hexagonal boron nitride monolayer under impact of a nano-projectile. Mechanics of Materials, 133, 1-12. https://doi.org/10.1016/j.mechmat.2019.03.003

\section{Published in:}

Mechanics of Materials

\section{Citing this paper}

Please note that where the full-text provided on Manchester Research Explorer is the Author Accepted Manuscript or Proof version this may differ from the final Published version. If citing, it is advised that you check and use the publisher's definitive version.

\section{General rights}

Copyright and moral rights for the publications made accessible in the Research Explorer are retained by the authors and/or other copyright owners and it is a condition of accessing publications that users recognise and abide by the legal requirements associated with these rights.

\section{Takedown policy}

If you believe that this document breaches copyright please refer to the University of Manchester's Takedown Procedures [http://man.ac.uk/04Y6Bo] or contact uml.scholarlycommunications@manchester.ac.uk providing relevant details, so we can investigate your claim.

\section{OPEN ACCESS}




\section{Accepted Manuscript}

Ballistic response of hexagonal boron nitride monolayer under impact of a nano-projectile

Hong Tian, Bin Zhang, Q.M. Li

PII: S0167-6636(18)30700-2

DOI: https://doi.org/10.1016/j.mechmat.2019.03.003

Reference: MECMAT 3015

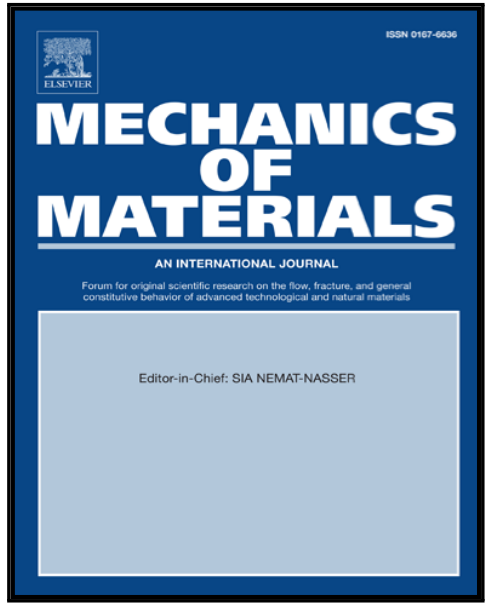

To appear in:

Mechanics of Materials

Received date:

11 October 2018

Revised date:

18 January 2019

Please cite this article as: Hong Tian, Bin Zhang, Q.M. Li, Ballistic response of hexagonal boron nitride monolayer under impact of a nano-projectile, Mechanics of Materials (2019), doi: https://doi.org/10.1016/j.mechmat.2019.03.003

This is a PDF file of an unedited manuscript that has been accepted for publication. As a service to our customers we are providing this early version of the manuscript. The manuscript will undergo copyediting, typesetting, and review of the resulting proof before it is published in its final form. Please note that during the production process errors may be discovered which could affect the content, and all legal disclaimers that apply to the journal pertain. 


\section{Highlights}

- A finite element model is developed for $h$-BN monolayer target, where the B-N bonds are represented by Timoshenko beam elements

- The elastic properties and bond strength of $h$-BN monolayer and graphene are verified by nano-indentation simulations

- The ballistic response of $h$-BN monolayer is dependent of the impact speed of the projectile

- The stress and deformation wave propagations in the $h$-BN monolayer interact with the movement of projectile and the material bond failure

- $h$-BN material has potential to increase the ballistic performance significantly for armor application 


\title{
Ballistic response of hexagonal boron nitride monolayer under impact of a nano-projectile
}

\author{
Hong Tian ${ }^{1}$, Bin Zhang ${ }^{1 *}$, Q.M. Li $^{2 *}$ \\ ${ }^{1}$ State Key Laboratory of Mechanics and Control of Mechanical Structures, and College of \\ Aerospace Engineering, Nanjing University of Aeronautics and Astronautics, Nanjing \\ 210016, China. \\ ${ }^{2}$ School of Mechanical, Aerospace and Civil Engineering, Pariser Building, The \\ University of Manchester, Sackville Street, Manchester M13 9PL, UK.
}

Abstract: The response of a hexagonal boron nitride ( $h$-BN) monolayer subjected to ballistic impact is studied using an explicit finite element (FE) model based on molecular structural mechanics where B-N bonds are represented by the nonlinear Timoshenko beam (B31) elements. The elastic properties and bond strength of $h$-BN monolayer and graphene are verified by nano-indentation using FE and molecular dynamics (MD) simulations. It shows that the ballistic response of $h$-BN monolayer is dependent of the impact speed of the projectile. The stress and deformation wave propagations in the $h$-BN monolayer interact with the movement of projectile and the material bond failure, which, in turn, influence the ballistic performance of the $h$ - $\mathrm{BN}$ monolayer target. It shows that $h$-BN material, in comparison with conventional armor materials, has potential to increase the ballistic performance significantly if it could be practically made for armor application.

Keywords $h$-BN monolayer; Nano-projectile impact; Dynamic responses; Ballistic limit; Energy dissipation

\footnotetext{
*Corresponding author.

Tel./fax: +86 25 84891422. E-mail address: beenchang@ @uaa.edu.cn (B. Zhang);

Tel.: +44 (0)1613065740. E-mail address: qingming.li@manchester.ac.uk (Q.M. Li).
} 


\section{Introduction}

Graphene and graphene-like two-dimensional (2D) crystals (e.g. boron nitride, transition metal dichalcogenides, black phosphorus) have attracted great attentions in recent years (Geim and Grigorieva, 2013; Shokrieh et al., 2017). These 2D monolayers can be stacked layer by layer to form various van der Waals hetero-structures (Geim and Grigorieva, 2013). Hexagonal boron nitride ( $h$-BN), so called "white graphene" (Rubio et al., 1994), is composed of alternating boron and nitrogen atoms in a honeycomb arrangement. The $h$-BN is complementary to graphene due to its large band-gap of $5.6 \mathrm{eV}$ (Kubota et al., 2007) in comparison with the zero band-gap of graphene (Partoens and Peeters, 2006). $h$-BN is also an ideal coating material (Haubner et al., 2002) due to its extraordinary thermal stability with rapid heat dissipation and chemical stability against oxidation to protect other underneath materials. In addition, $h$-BN has superior mechanical properties of high longitudinal strength, high in-plane stiffness and low lateral stiffness (i.e. good flexibility in out-of-plane direction), which as impact-resistant material could be added to armor components eoatings to enhance ballistic protection effectively (Zhang and Zhang, 2015; Acar et al., 2018; Partoens and Peeters, 2018). Meanwhile, mass production technology for high-quality $h$-BN layers at acceptable costs has been available (Lu et al., 2015) in comparison with the manufacture of other graphene-like materials, e.g., $\mathrm{MoS}_{2}$

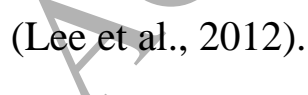

Ballistic performance of graphene target has been studied in recent years. Lee et al. (2014) performed an innovative experiment by ejecting a micro-scale projectile towards the graphene multilayer (about 30-300 layers) at impact speeds of $600 \mathrm{~m} / \mathrm{s}$ and $900 \mathrm{~m} / \mathrm{s}$. The specific penetration energy $E_{\mathrm{p}}^{*}$ of graphene multilayer target was found to be 
approximately 10 times that of steel target. Based on a membrane analysis proposed by Phoenix et al. (2003) and the uniaxial mechanical behaviors of graphene using ab initio density functional theory (DFT), Wetzel et al. (2015) predicted the ballistic resistance of graphene and showed that multilayer graphene could achieve ballistic performance of the existing armor materials, e.g. Kevlar 129, with significant reduction of areal density of about two orders. Yoon et al. (2016) revealed that the maximum allowable deformation of graphene before crack initiation is attributed to its superior specific penetration energy determined by its high ultimate stress and strain. Meanwhile, fast load and momentum transfers in graphene due to the high speed of stress wave propagation was demonstrated by Haque et al. (2016) where the cone-wave and axial-wave speeds were calculated using molecular dynamic (MD) simulations, which is another way to involve more materials to resist local impact.

Conventional methods have their respective limitations in estimating the dynamic behaviors of 2D materials. Ballistic experiment on 2D material target is expensive and difficult due to the preparation of a suspended and large-area thin film, the characterization at the atomistic level, and the control and track of a micro- or nano-sized projectile. Atomistic computations, e.g. Quantum mechanics (DFT) and MD methods, are usually limited by CPU time and modeling size. Therefore, a finite element method (FEM) is combined with the molecular structural mechanics approach ( $\mathrm{Li}$ and Chou, 2003) in this study to simulate the response of monolayer $h$-BN under the impact of a nano-projectile where the structural elements (i.e. beam or rod) are characterized by the B-N bonds. Because the Euler-Bernoulli beam model is only suitable for geometric nonlinear analysis 
with small strain and large rotation (Tserpes et al., 2006; Baykasoglu and Mugan, 2012), Timoshenko beam model is used here to represent B-N bonds to avoid the overestimation of beam deflection (Scarpa and Adhikari, 2008; Boldrin et al., 2011). The latter can also consider shear deformation and Poisson's ratio effects of the equivalent continuum material. Furthermore, the modified Tersoff-Brenner potential (Tersoff, 1988; Brenner, 1990; Oh, 2010) is employed in FEM to generate the stiffness matrix by optimizing the cutoff function (taken as unity) and shifting the cutoff distance (Kumar et al., 2016), which eliminates the fictitious dramatic rise in bond stretch force.

This paper is organized with following structure. In Section 2, a ballistic FE model for $h$-BN monolayer is established and verified by nano-indentation at low speed as a special case of the ballistic impact. Section 3 studied the ballistic responses of $h$-BN monolayer under nano-projectile impact with focus on the spring-back, perforation, propagations of stress waves, crack patterns, and energy dissipation mechanisms in the $h$-BN monolayer target. This is followed by conclusions in Section 4.

\section{FE modeling methodology and simulations}

\subsection{Equivalent nonlinear B31 elements for B-N bonds}

Under the assumption of small deformation, a simplified harmonic potential is used to describe the energy of B-N bond, and by equating the bond energy to the strain energy of a three-dimensional two-node linear Timoshenko beam element (B31 in ABAQUS), the relations between force constants in molecular mechanics and sectional stiffness parameters in structural mechanics are established as (Boldrin et al., 2011; Zhang et al., 


$$
k_{r}=\frac{\pi E d_{0}^{2}}{4 l_{0}}, k_{\theta}=\frac{E I}{l_{0}} \frac{4+\Phi}{1+\Phi}, k_{\tau}=\frac{G J}{l_{0}}
$$

where $k_{r}, k_{\theta}$ and $k_{\tau}$ are the bond stretching, bending and torsion force constants; $E$ and $G$ are the Young's modulus and shear modulus of the equivalent beam material; $d_{0}$ is the diameter of B31 element with circular cross-section (inertia moment $I=\pi d_{0}^{4} / 64$, polar inertia moment $J=\pi d_{0}^{4} / 32$ ) and $l_{0}$ is the beam length; $\Phi$ represents the shear deformation constant. For a large deformation problem with geometric nonlinear effects, Tersoff-Brenner potential (Tersoff, 1988; Brenner, 1990) with the adjusted potential parameters $(\mathrm{Oh}, 2010)$ is employed to describe the nonlinear behaviors of Timoshenko beam models (B-N bonds), i.e.

$$
\sigma_{\mathrm{BN}}=\frac{F_{\mathrm{BN}}}{A_{\mathrm{BN}}}=\frac{\partial U_{\mathrm{BN}} / \partial r_{\mathrm{BN}}}{A_{\mathrm{BN}}} \approx \frac{290}{A_{\mathrm{BN}}}\left(-\exp \left(-4.682 \varepsilon_{\mathrm{BN}}\right)+\exp \left(-4.347 \varepsilon_{\mathrm{BN}}\right)\right),
$$

where $A_{\mathrm{BN}}\left(=\pi d_{0}^{2} / 4\right)$ is the cross-sectional area; $r_{\mathrm{BN}}$ is the bond length, equaling to $r_{\mathrm{BN} 0}\left(1+\varepsilon_{\mathrm{BN}}\right) ; r_{\mathrm{BN} 0}$ is the equilibrium bond length (taking $l_{0}=r_{\mathrm{BN} 0}, 1.45 \AA$ for $\mathrm{B}-\mathrm{N}$ bond (Tian et al., 2018) and 1.42 Å for C-C bond (Zhang et al., 2015)). It should be noted that necessary modifications are made in Eq. (2) to avoid the overestimation of unphysical stress and strain in atomistic structure, i.e. removing the cutoff function $\left(f_{\mathrm{c}}\left(r_{\mathrm{BN}}\right)=1\right)$ from the potential function $\left(U_{\mathrm{BN}}\left(r_{\mathrm{BN}}\right)\right)$, shifting the cutoff distance to $1.77 \AA$ (1.76 $\mathrm{\AA}$ in (Wu et al., 2013)). The stress-strain curve is plotted in Fig. 1 , and the peak stress $\sigma_{\mathrm{c}}=1.89 \mathrm{TPa}$ at strain $23.70 \%$ is taken as the failure criterion for B31 element Taking the derivative of $\sigma_{\mathrm{BN}}$ with respect to $\varepsilon_{\mathrm{BN}}$, the Young's module $E$ is expressed by

$$
E_{\mathrm{BN}}=\left.\frac{\partial \sigma_{\mathrm{BN}}}{\partial \varepsilon_{\mathrm{BN}}}\right|_{\varepsilon_{\mathrm{BN}}=0}=\frac{97.15}{A_{\mathrm{BN}}}
$$

Based on Eqs. (1) and (3), with the known force constants (Boldrin et al., 2011; Zhang et 
al., 2015; Tian et al., 2018), the physical and geometric parameters of B31 element are calculated and listed in Table 1. More details can be found in (Tian et al., 2018).

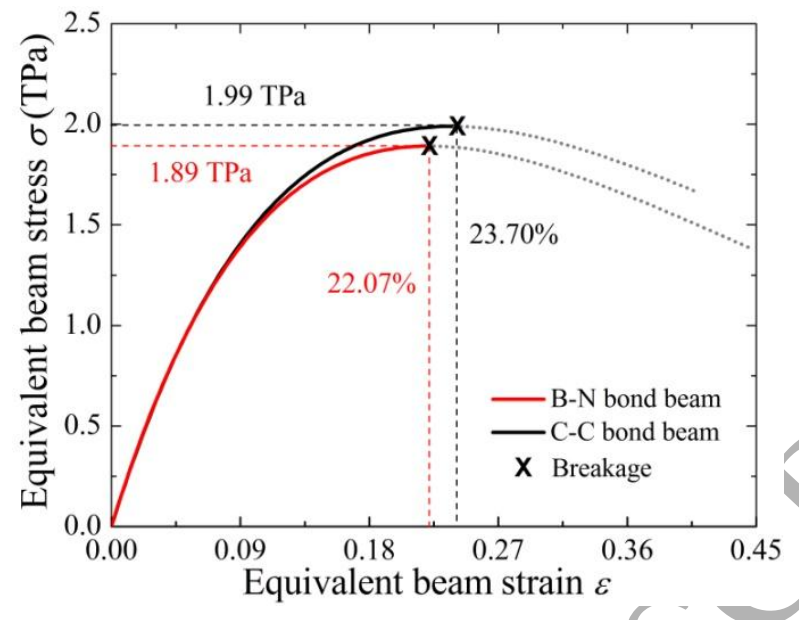

Fig. 1. The nonlinear constitutive relations of equivalent beams for B-N and $\mathrm{C}-\mathrm{C}$ bonds, derived from the modified Tersoff-Brenner potential. The failed element will be deleted once B31 stress or strain reaches the critical values at peaks for B-N bond beam $(1.89 \mathrm{TPa}, 22.07 \%)$ and for $\mathrm{C}-\mathrm{C}$ bond beam (1.99 TPa, 23.70\%) labeled by cross points.

\section{Table 1}

The physical and mechanical parameters of equivalent B 31 elements for B-N and C-C bonds.

\begin{tabular}{cccccc}
\hline Materials & $l_{0}(\AA)$ & $d_{0}(\AA)$ & $E(\mathrm{GPa})$ & $v$ & $\Phi$ \\
\hline$h$-BN & 1.45 & 0.73 & 23212 & 0.213 & 0.418 \\
Graphene & 1.42 & 0.78 & 22811 & 0.216 & 0.499 \\
\hline
\end{tabular}

\subsection{Simulations of nano-projectile impact on $h$-BN monolayer and verifications}

For maximizing the reflected cone wave effect, the FE model of $h$-BN monolayer with eireular shape is constructed in a circle with radius $R \sim 201 \AA$ (Fig. 2c), with the edge nodes fully fixed (boundary condition). It is comprised of 70026 B31 elements and 46869 nodes where around $95 \%$ atomistic mass is deployed at nodes to mimic the real material (Zhang et al., 2015; Tian et al., 2018). The nano-projectile (Fig. 2 d) with radius $r_{\mathrm{p}}=16.70$ $\AA$ and density $7850 \mathrm{~kg} / \mathrm{m}^{3}$ is modeled by rigid solid elements. Thus, the impact energy is only dissipated by target. We define the master surface on the hemispherical projectile, 
and the slave nodes on a central region of monolayer $h$-BN within radius $2 r_{\mathrm{p}}$ to establish the node-to-surface hard contact without friction . FE simulations of monolayer $h$-BN under the transverse impact of nano-projectile are conducted using ABAQUS/Explicit (Hibbit, 2009). The time step $0.0001 \mathrm{ps}$ is used for convergence efficiency while the time step scale factor is set as 0.9 (Lim et al., 2003) for numerical stability. Through VUMAT subroutine, the secant modulus of B31 element shown in Fig. 1 and node coordinates in $h$-BN model are updated at each loading time step. The beam element will be deleted once its axial stress reaches $1.89 \mathrm{TPa}$.

Before the study of the ballistic behaviors of $h$-BN monolayer, its tensile behavior is studied by FE and MD simulations of nano-indentation at a speed of $0.5 \AA$ ^s (Fig. $2 \mathrm{~d}$ and e). Ballistic nano-indentation is inherently a low-speed test (Lee et al., 2014), but strain-rates can reach $10^{5} \sim 10^{6} \mathrm{~s}^{-1}$ for very thin samples (Gotsmann et al., 2008). The original cutoff function and cutoff distance of $2.1 \AA$ are adopted in MD simulation to compare with FE results using the modified parameters. The van der Waals forces between rigid indenter and $h$ - $\mathrm{BN}$ monolayer are simulated by the Lennard-Jones potential. MD simulations are performed using LAMMPS package (http://lammps.sandia.gov) (Plimpton, 1995) after relaxing for $100 \mathrm{ps}$ in the shown (NVT at absolute zero temperature ).

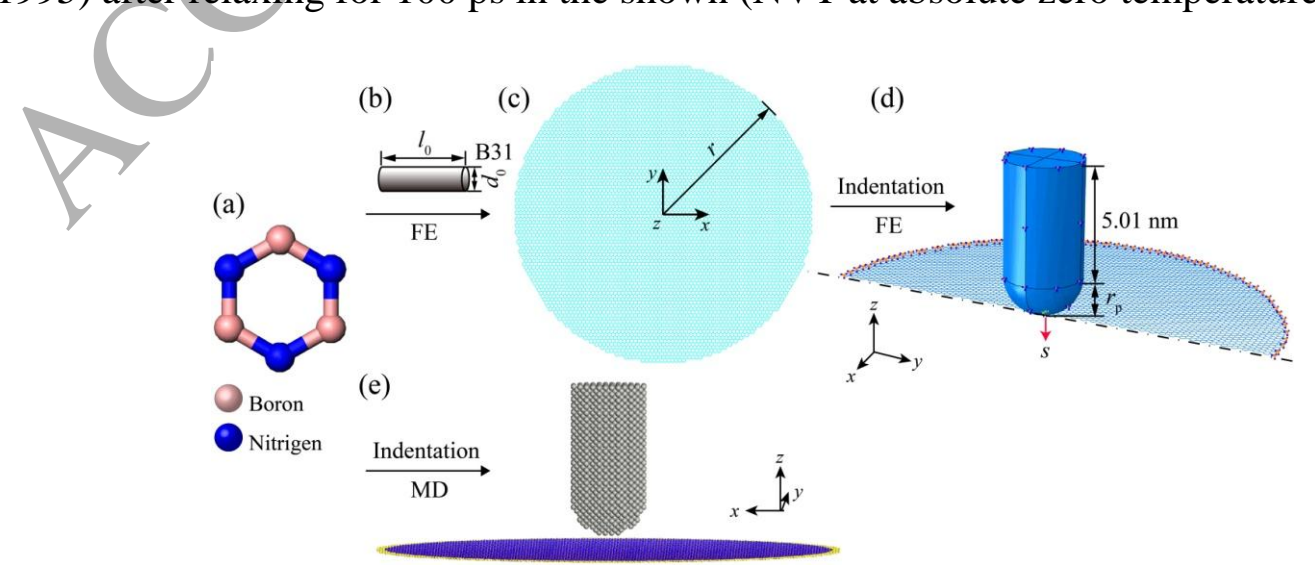

Fig. 2. (a) Primitive cell of $h$-BN crystal; (b) Equivalent B31 element for B-N bond with cross-section 
diameter $d_{0}$ and beam length $l_{0}$; (c) FE model for circular $h$-BN monolayer with radius $r$; (d) Schematics of FE model for nano-indentation on $h$-BN monolayer by a rigid indenter with hemispherical nose radius of $r_{\mathrm{p}} \approx(1 / 6) r$ (Tan et al., 2013; Wang et al., 2014), (e) MD model corresponding to the FE model in (d).

For a fully clamped circular monolayer under the center point loading, shown in Fig. 2d and e, the load-displacement behavior can be approximated by (Lee et al., 2008; Wan et al., 2003; Komaragiri et al., 2005)

$$
F=\sigma_{0}^{2 \mathrm{D}} \pi r\left(\frac{\delta}{r}\right)+E^{2 \mathrm{D}}\left(q^{3} r\right)\left(\frac{\delta}{r}\right)^{3},
$$

where $F$ and $\delta$ denote the indentation load and the central deflection of the monolayer, respectively. The first part is eaused by the axial tension term determined by $\delta$, pretension $\sigma_{0}^{2 \mathrm{D}}$ and monolayer radius $r(\sim 100.5 \AA)$; the second part is the large deformation term, related to $\delta, r, 2 \mathrm{D}$ linear Young's modulus $E^{2 \mathrm{D}}$, and the dimensionless constant $q=1 /\left(1.05-0.15 v_{\mathrm{t}}-0.16 v_{\mathrm{t}}^{2}\right) \quad$ where values of Poisson's ratio $v_{\mathrm{t}}$ are 0.284 for $h$-BN (Tian et al., 2018), and 0.165 for graphene (Zhang et al., 2015; Lee et al., 2008)), respectively. $E^{2 \mathrm{D}}$ and $\sigma_{0}^{2 \mathrm{D}}$ can be extracted by fitting the simulation data with Eq. (4), . Both experimental (Lee et al., 2008) and computational (Wetzel et al., 2015) studies have shown that the nonlinear elastic behavior of 2D crystals under axial tension can be described by

$$
\sigma^{2 \mathrm{D}}=E^{2 \mathrm{D}} \varepsilon^{+} D^{2 \mathrm{D}} \varepsilon^{2}
$$

where $D^{2 \mathrm{D}}$ is the $2 \mathrm{D}$ nonlinear elastic modulus. Thus, the maximum stress $\sigma_{\mathrm{m}}^{2 \mathrm{D}}=\left(E^{2 \mathrm{D}}\right)^{2} / 4 D^{2 \mathrm{D}}$ occurs at $\varepsilon_{\mathrm{m}}=-E^{2 \mathrm{D}} / 2 D^{2 \mathrm{D}}$. The maximum stress for this circular monolayer can also be estimated by (Bhatia and Nachbar, 1968)

$$
\sigma_{\mathrm{m}}^{2 \mathrm{D}}=\left(\frac{F^{\mathrm{C}} E^{2 \mathrm{D}}}{4 \pi r_{\mathrm{p}}}\right)^{1 / 2}
$$

where $r_{\mathrm{p}}$ is the projectile nose radius and $F^{\mathrm{C}}$ is the breaking force. The value of $F^{\mathrm{C}}$ for monolayer $h$ - $\mathrm{BN}$ is $80.192 \mathrm{nN}(115.806 \mathrm{nN}$ for graphene) in FE simulation, and 438.908 
$\mathrm{nN}(655.477 \mathrm{nN}$ for graphene (Wang et al., 2014)) in MD simulation, corresponding to the ultimate indentation depth of $3.079 \mathrm{~nm}$ (3.354 nm for graphene) in FE simulation and 5.0 $\mathrm{nm}$ (5.6 nm for graphene (Wang et al., 2014)) in MD simulation, respectively, as shown in Fig. 3. The common pretension and elastic modulus of a 3D material can be calculated by diving their respective $2 \mathrm{D}$ values by the effective thickness $h_{\mathrm{t}}$, (i.e. the interlayer spacing distances of bulk BN/graphite, which are $0.33 \mathrm{~nm}$ for $h$-BN (Bosak et al., 2006) and 0.335 nm for graphene (Al-Jishi and Dresselhaus, 1982), as shown in Table 2. It can be found that the simulated value of $\sigma_{\mathrm{m}}(\sim \mathrm{E} / 8)$ is close to $\mathrm{E} / 9$, obtained by extrapolation in (Griffith, 1921).

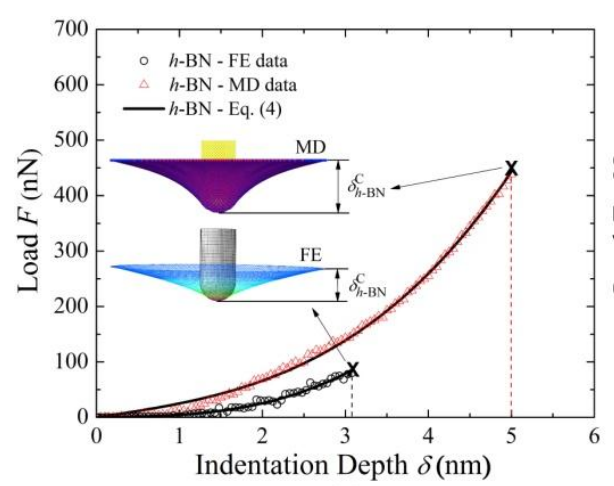

(a)

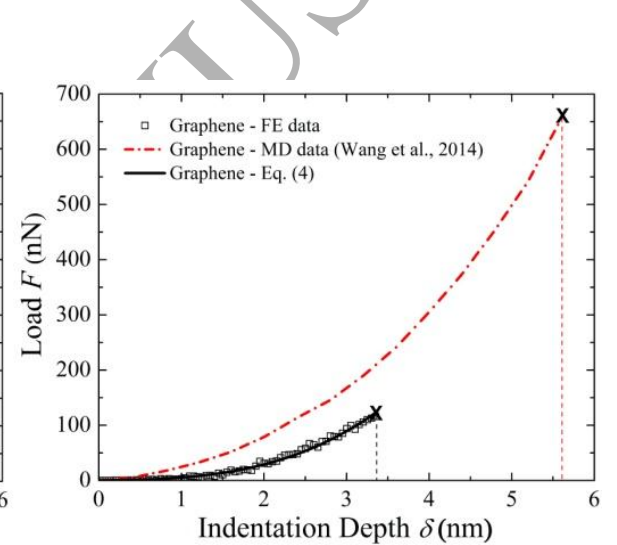

(b)

Fig. 3. Load-deflection data for the indentation of monolayer target, (a) $h$-BN; (b) graphene, with curves fitted by Eq. (4). Cross signs represent the critical forces of monolayer $h$-BN/graphene before failure. 


\section{Table 2}

Mechanical properties of $h$-BN/graphene obtained by FE and MD simulations of nano-indentation, comparing with results from MD (Wang et al., 2014), experiments (Bosak et al., 2006; Lee et al., 2008) and DFT (Peng et al., 2012) methods.

\begin{tabular}{|c|c|c|c|c|c|c|c|c|}
\hline Materials & Methods & $\begin{array}{l}\sigma_{0}^{2 \mathrm{D}} \\
(\mathrm{N} / \mathrm{m})\end{array}$ & $\begin{array}{l}E^{2 \mathrm{D}} \\
(\mathrm{N} / \mathrm{m})\end{array}$ & $\begin{array}{l}E \\
(\mathrm{TPa})\end{array}$ & $\begin{array}{l}D^{2 \mathrm{D}} \\
(\mathrm{N} / \mathrm{m})\end{array}$ & $\begin{array}{l}D \\
(\mathrm{TPa})\end{array}$ & $\begin{array}{l}\sigma_{\mathrm{m}}^{2 \mathrm{D}} \\
(\mathrm{N} / \mathrm{m})\end{array}$ & $\begin{array}{l}\sigma_{\mathrm{m}} \\
(\mathrm{GPa})\end{array}$ \\
\hline \multirow{4}{*}{$h$-BN } & $\mathrm{FE}^{\text {this work }}$ & 0.637 & 268.07 & 0.812 & -561.32 & -1.701 & & 96.99 \\
\hline & $\mathrm{MD}^{\text {this work }}$ & 7.151 & 262.25 & 0.795 & -232.16 & -0.704 & & 224.42 \\
\hline & Experiment ${ }^{\text {Bosak et al. }}$ & - & 252.76 & 0.766 & - & & & - \\
\hline & $\mathrm{DFT}^{\text {Peng et al. }}$ & - & 279.2 & 0.846 & - & & & 84.27 \\
\hline \multirow{3}{*}{ Graphene } & $\mathrm{FE}^{\text {this work }}$ & 0.715 & 330.19 & 0.986 & -638.53 & -1 . & 42.69 & 127.42 \\
\hline & MD Wang et al. & 38.859 & 375.01 & 1.119 & & -1.448 & 72.48 & 216.36 \\
\hline & Experiment ${ }^{\text {Lee et al. }}$ & $0.07-0.74$ & $340 \pm 50$ & $1.0 \pm 0.1$ & -6 & $-2.0 \pm 0.4$ & $42 \pm 4$ & $130 \pm 10$ \\
\hline
\end{tabular}

Agreements between FE results and those from experiments and theoretical calculations

(Bosak et al., 2006; Peng et al., 2012; Wang et al., 2014; Lee et al., 2008) in Table 2 verify the rationality and reliability of the equivalent FE model. The overestimated maximum stress by MD in comparison with the prediction by FE model is caused by the large cutoff distance chosen from (Oh, 2010; Wu et al., 2013; Han et al., 2014), leading to the large indentation depth and breaking force, as shown in Fig. 3. The Young's modulus obtained by FE is consistent with that predicted by MD simulation. The computational cost of FE is less than the cost of MD because there is no need for energy minimization and equilibrium with large amount of atoms.

\section{Results and discussion}

\subsection{Ballistic limit of monolayer $h-B N$}

Based on massive simulations, the dependence of residual speed of projectile $V_{\mathrm{r}}$ on the impact speed $V_{\mathrm{i}}$ is shown in Fig. 4, which is fitted by the Lambert-Jonas formula (Lambert 
and Jonas, 1976)

$$
V_{\mathrm{r}}=a\left(V_{\mathrm{i}}^{p}-V_{\mathrm{bl}}^{p}\right)^{1 / p}
$$

where $V_{\mathrm{bl}}$ is the ballistic limit; $p$ is a fitting parameter; $a=m_{\mathrm{p}} /\left(m_{\mathrm{p}}+m_{\mathrm{pug}}\right)$ with $m_{\text {plug }}$, the mass of the shear plug ejected from target, and $m_{\mathrm{p}}$, the mass of projectile. The ballistic resistance is dependent on the impact oblique angle. The increase of angle may cause the increase of in-plane force for resisting the displacement of projectile parallel to target. Thus the target may be perforated before the impact energy is delocalized by global deflection. In this work, we focus on the ballistic limit of $h$-BN monolayer under normal impact, which is predicted as $1139 \mathrm{~m} / \mathrm{s}$. The material parameter $\Lambda_{\mathrm{m}}$, a scaling factor proposed by Cunniff (1999), is used here to evaluate the ballistic limit of $h$-BN as compared with graphene

$$
\Lambda_{\mathrm{m}}=\left(\bar{U}_{\mathrm{m}} \cdot C_{\mathrm{L}}\right)^{1 / 3}
$$

where $\bar{U}_{\mathrm{m}}=U_{\mathrm{m}} / \rho^{2 \mathrm{D}}(\mathrm{J} / \mathrm{g})$ is the mass-normalized strain energy at failure; $\rho^{2 \mathrm{D}}$ is the $2 \mathrm{D}$ density of monolayer. By integrating Eq. (5) with respect to strain, the strain energy density $U$ is determined as

$$
U=\frac{1}{2} E^{2 \mathrm{D}} \varepsilon^{2}+\frac{1}{3} D^{2 \mathrm{D}} \varepsilon^{3}
$$

Therefore, the area-normalized strain energy at $\varepsilon=\varepsilon_{\mathrm{m}}$ is expressed by $U_{\mathrm{m}}=4\left(\sigma_{\mathrm{m}}^{2 \mathrm{D}}\right)^{2} / 3 E^{2 \mathrm{D}}$ $\left(\mathrm{J} / \mathrm{m}^{2}\right)$. By Ref. (Wetzel et al., 2015), using the scaling factor of $h$-BN divided by that of graphene, the ballistic limit of $h$-BN is predicted as 0.86 that of graphene, approximately 10 times that of Kevlar 129 ( $V_{\text {bl-graphene }} \sim 11.6 \times V_{\text {bl-Kevlar }}$ in (Wetzel et al., 2015)). From Table 3, we found that $h$-BN membrane, similarly to graphene, is an excellent light-weight armor material due to its low density, high strength, superior in-plane wave speed and the remarkable ballistic limit. 


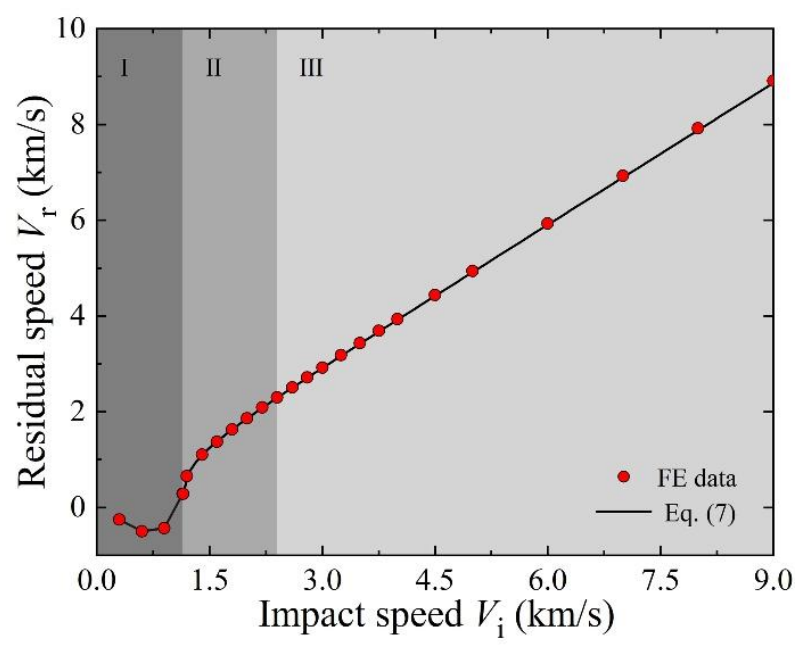

Fig. 4. Relationship between the impact and residual speeds of nano-projectile.

Table 3

The mechanical properties and ballistic limits $V_{\mathrm{bl}}$ of monolayer $h$-BN and graphene.

\begin{tabular}{llllllll}
\hline Materials & $\begin{array}{l}\rho \\
\left(\mathrm{g} / \mathrm{cm}^{3}\right)\end{array}$ & $\begin{array}{l}E \\
(\mathrm{GPa})\end{array}$ & $\begin{array}{l}\sigma_{\mathrm{m}} \\
(\mathrm{GPa})\end{array}$ & $\begin{array}{l}\varepsilon_{\mathrm{m}} \\
(\%)\end{array}$ & $\begin{array}{l}C_{\mathrm{L}} \\
(\mathrm{km} / \mathrm{s})\end{array}$ & $\begin{array}{l}\Lambda_{\mathrm{m}} \\
(\mathrm{m} / \mathrm{s})\end{array}$ & $\begin{array}{l}V_{\mathrm{bl}} \\
/ V_{\mathrm{bl} \text {-graphene }}\end{array}$ \\
\hline Graphene & 2.271 & 986 & 127.04 & 25.9 & 20.84 & $5857\left(5054^{\text {Wetzel et al. })}\right.$ & 1 \\
$h$-BN & 2.286 & 812 & 96.99 & 23.9 & 19.16 & 5058 & 0.86 \\
\hline
\end{tabular}

3.2 Dynamic responses of monolayer $h-B N$ when $V_{i} \leq V_{b l}$

When monolayer $h$-BN target is impacted by a nano-projectile at low speed, i.e. $V_{\mathrm{i}} \leq$ $V_{\mathrm{bl}}$, the response and the reaction force-time history are shown in Figs. 5a-5d, based on which, the response process can be divided into four stages, i.e.

Stage-I $\left(0 \leq t \leq t_{1}\right)$ from the moment of impact to the first peak reaction force: The $h$-BN target deforms rapidly into a conic shape when the local beam elements are stretched and the bonding force is increased within its elastic limit. There is a stress concentration area around the striking point, from which a longitudinal stress wave propagates outward at speed of $C_{\mathrm{L}}$, a transverse stress wave propagates at a lower speed of $C_{\mathrm{T}}$, and a conic deformation boundary of the target (so-called cone wave) propagates at a speed of $C_{\mathrm{k}}$, which is much lower than $C_{\mathrm{L}}$ and $C_{\mathrm{T}}$. Both longitudinal and transverse stress waves 
transfer the momentum fast, and the cone wave (distinguished by the stress distribution in Fig. 5i referring to the color-scale bar) mainly transfers the load towards the fixed boundary, characterized by an obvious conic shape and its increasingly occupied conic area following the cone wave, as shown by snapshot (i) in Fig. 5c.

Stage-II $\left(t_{1}<t \leq t_{2}\right)$ where $t_{2}$ is defined by as the time when projectile speed equaling zero, at which the impact center reaches a maximum deflection along its indentation direction as shown in snapshot (ii) in Fig. 5c. During this stage, the $h$-BN target keeps contact with projectile, and the reaction force starts to decrease from the first/peak because the propagation of the cone wave plays an important role to relief the reaction force due to bond stretching. Most of the total kinetic energy of projectile is transformed into the deformation potential energy relative to the vibration energy of nodes in Stages-I and II, which will be shown quantitatively in Section 3.4.

Stage-III $\left(t_{2}<t \leq t_{3}\right)$ where $t_{3}$ is defined by as the time at which the force and projectile speed (acceleration) increase suddenly. The cone wave is reflected from the circular clamped boundary towards the projectile (arrows labeled in snapshot (ii) in Fig. 5c), which localizes the stretching deformation into a reduced area, as shown between snapshots (ii) and (iii). The reduced cone of $h$-BN monolayer further pushes the projectile to rise its rebounding speed until a short separation happens between the projectile and $h$-BN monolayer (i.e. the short plateau in $V_{\mathrm{p}}-t$ curve and the associated nearly-zero reaction force). Then, the reflected wave in $h$ - $\mathrm{BN}$ monolayer meets at the centre and gives projectile a big push (i.e. the reaction force reaches the second peak), and the reaction force deforms the monolayer and generates large local strain that leads to an immediate 
perforation of monolayer (i.e. the reaction bond force exceeds the bond breaking force of $80.192 \mathrm{nN}$ and the bond length exceeds the optimized cutoff distance), shown by snapshot (iv) in Fig. 5b. The slight inclination of projectile towards negative $y$ axis in $y z$ plane is caused by the fact that the target model (hexagonal tiling) has unsymmetrical nodes about $x$ axis (Fig. 2), leading to unsymmetrical deformation.

Stage-IV $\left(t_{3}<t \leq t_{4}\right)$ where $t_{4}$ is defined at the moment when the speed becomes constant (force becomes zero), corresponding to snapshot (iv) in Fig. 5a when the projectile is bounced off the $h$-BN target. It is interesting to note that the stress waves spread the kinetic energy of projectile efficiently away from the striking region. In other words, the outstanding ballistic performance of $h$-BN monolayer, e.g. superior ballistic limit, results from not only the high ultimate stress and strain of $h$-BN monolayer (Table 2) but also the high speed of stress wave propagation (Table 4). However, once the reflected cone wave returns from the fully clamped boundary, the localized deformation may break the inter-atomic bond and cause perforation in the rebounding stage even when $V_{\mathrm{i}} \leq V_{\mathrm{bl}}$. 


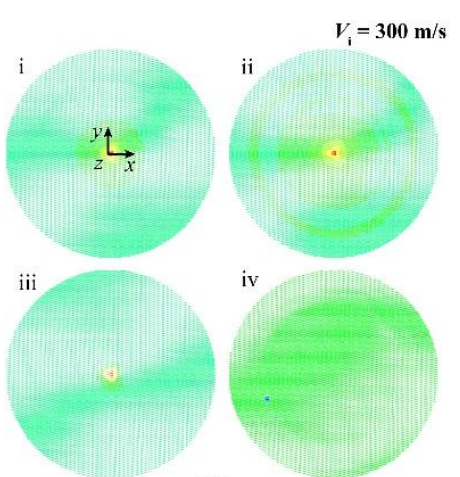

(a)

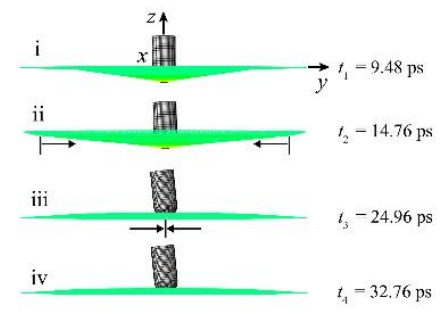

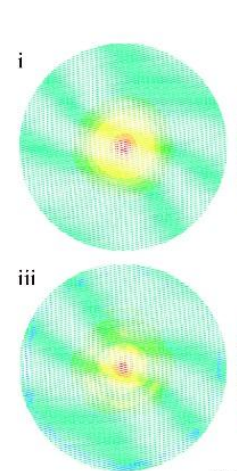

(b)

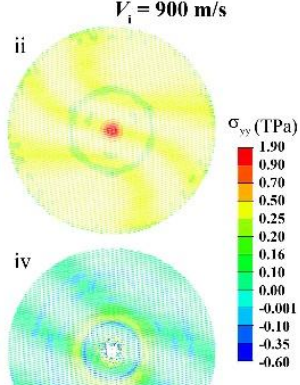

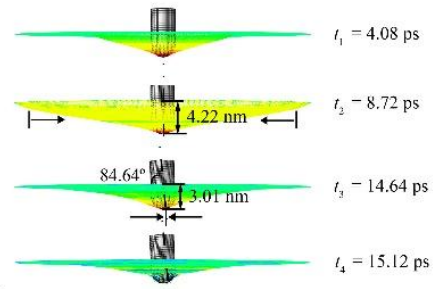

(c)

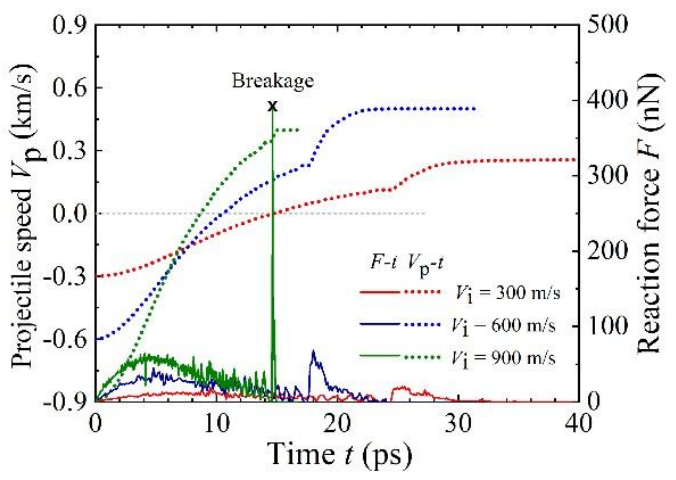

(d)

Fig. 5. Snapshots during rebounding, top views at low impact speeds of (a) $V_{\mathrm{i}}=300 \mathrm{~m} / \mathrm{s}$, and (b) $V_{\mathrm{i}}=$ $900 \mathrm{~m} / \mathrm{s}$; (c) main views at time i) $t_{1}$, ii) $t_{2}$, iii) $t_{3}$ and iv) $t_{4}$ for $V_{\mathrm{i}}=300 \mathrm{~m} / \mathrm{s}$ (left) and $V_{\mathrm{i}}=900 \mathrm{~m} / \mathrm{s}$ (right); (d) Curves of projectile speed/reaction force versus time, the cross point shows the immediate failure of $h$-BN monolayer at $900 \mathrm{~m} / \mathrm{s}$ (Note: The color-scale bar in Figs. 5a and $5 \mathrm{~b}$ measures the magnitude of B31 axial stresses $\sigma_{\text {yy }}$ in local coordinates).

\subsection{Stress wave effects when $V_{i}>V_{b l}$}

The stress wave effects on the dynamic response of monolayer $h$-BN during perforation at high impact speed (i.e. $V_{\mathrm{i}}>V_{\mathrm{bl}}$ ) are investigated numerically. Taking $V_{\mathrm{i}}=2400 \mathrm{~m} / \mathrm{s}$ as an example, once $h$-BN target is impacted by a projectile, a tensile wave of hexagonal shape (distinguished by contour) spreads outwards at $C_{\mathrm{L} 1}$, which is followed by a cone (kink)-wave propagating at a lower speed of $C_{\mathrm{k}}$, as shown in Fig. 6a. During the propagation of the cone wave, $h$-BN target is perforated due to the initiation of cracks at 
center, which propagate to the kink boundary of the cone wave. As soon as the crack is initiated, an unloading wave with speed $C_{\mathrm{L} 2}\left(=C_{\mathrm{L} 1}\right)$ emerges due to the rapid relaxation of elastic deformation, as shown in Fig. 6b. A reference node $\mathrm{A}$ is set in the middle of radius along the radial direction. Fig. $6 \mathrm{c}$ shows the moment when the compress wave is passing node A where the crack propagation can also be observed. Fig. 6d corresponds to the moment when the unloading wave is reflected by the fixed boundary and Fig. 6e is the moment when the reflected unloading wave passes node A again in the opposite direction. Then, multiple wave reflections between fixed boundary and free boundary (cracked perforation hole) happen until the trapped momentum is dissipated and an equilibrium state is established. Fig. $6 \mathrm{f}$ depicts the failure modes of $h$-BN target, i.e. six petalling cracks with tiny debris. Each petal is folded at its base and creased by snap-backing when the elastic extension is rapidly relaxed along radial direction. According to Lee et al. (2014), the maximum crack length, $L_{\max }$, is recorded to estimate the final radius of the conic perforation hole.

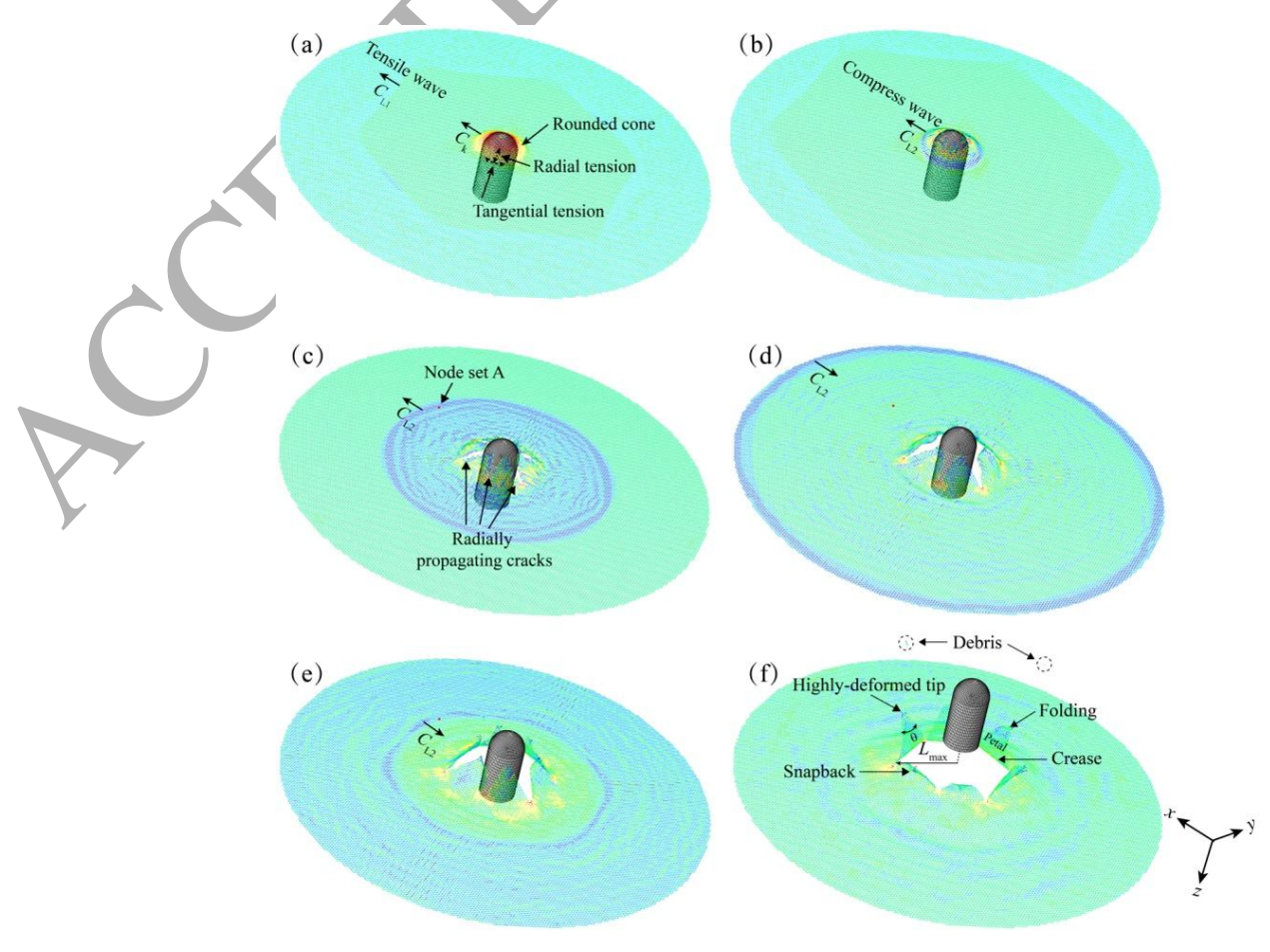


Fig. 6. Series of dynamic events at impact speed of $2400 \mathrm{~m} / \mathrm{s}$. Snapshots (an oblique view from the bottom side) of (a) cone wave propagation at time $0.58 \mathrm{ps}$; (b) unloading (compression) wave formation at $0.76 \mathrm{ps}$; (c) the moment when the unloading wave passes node $\mathrm{A}$ at $1.12 \mathrm{ps}$; (d) reflection at fixed boundary at $1.70 \mathrm{ps}$; (e) the moment when the reflected unloading wave re-passes node A at $2.14 \mathrm{ps}$, and (f) the perforated target at $4.92 \mathrm{ps}$.

For an elastic membrane under the transverse impact of projectile, the speeds of longitudinal and transverse waves along the material directions 1 and 2 (aligned with geometric axes $x$ and $y$ ) can be calculated by (Haque et al., 2016)

$$
\begin{gathered}
C_{\mathrm{L}}=\sqrt{\frac{E}{\left(1-v^{2}\right) \rho_{\mathrm{t}}}}, \\
C_{\mathrm{T}}=\sqrt{\frac{E}{2(1+v) \rho_{\mathrm{t}}}}
\end{gathered}
$$

where $\rho_{\mathrm{t}}=2286 \mathrm{~kg} / \mathrm{m}^{3}$ and $E_{11}=776 \mathrm{GPa}, v_{12}=0.260, E_{22}=812 \mathrm{GPa}, v_{21}=0.307$ obtained by FE simulations of $h$-BN monolayer under axial tension (Tian et al., 2018). The wave speeds are determined as $C_{\mathrm{L}}=19.44 \mathrm{~km} / \mathrm{s}$ and $C_{\mathrm{T}}=11.64 \mathrm{~km} / \mathrm{s}$ for $h$-BN monolayer (Table 4) due to its relatively low density along with high modulus; in contrast, $C_{\mathrm{L}}=5.9$ $\mathrm{km} / \mathrm{s}$ and $C_{\mathrm{T}}=3.2 \mathrm{~km} / \mathrm{s}$ for steel $\left(\rho_{\text {steel }}=79000 \mathrm{~kg} / \mathrm{m}^{3}, E_{\text {steel }}=200 \mathrm{GPa}\right)$. The speed of cone wave is estimated as (Lee et al., 2014)

$$
C_{\mathrm{k}} \approx 0.976 C_{\mathrm{L}}\left(\frac{V_{\mathrm{i}}}{C_{\mathrm{L}}}\right)^{2 / 3}
$$

The theoretical value of $C_{\mathrm{k}}$ reaches $24 \%-58 \% C_{\mathrm{L}}\left(40 \%-97 \% C_{\mathrm{T}}\right)$ when $V_{\mathrm{i}}$ is in the range of $2.4 \mathrm{~km} / \mathrm{s}-9.0 \mathrm{~km} / \mathrm{s}$. It means that, with the increase of impact speed, cone wave plays a more important role in quick response (conic deformation and damage) to an extreme load and fast transfer of projectile momentum. The wave speeds can also be calculated from the deformation of the target caused by wave propagations. Fig. 7a is the $1 / 4$ model of $h$-BN 
monolayer. Fig. $7 \mathrm{~b}$ shows the transverse displacements of nodes in positive $x$-axis at time 1.70 ps (Fig. 6d) when the unloading wave is just reflected. According to Fig. 7b, the nodes along positive $x$-axis are classified into three regions, i.e. Region-I, where the nodal $z$-displacements are obvious and mainly caused by conic deformation (the effect of transverse wave on z-displacement is so weak that it can be ignored). Region-II, where the $z$-displacements are caused by transverse wave propagation until the arrival of the cone wave ( $t \leq 1.70 \mathrm{ps}$ ). Region-III, where longitudinal wave propagates at the fastest speed and only leads to the $x$-displacements of nodes $\left(u_{z}=0\right.$ in Fig. 7b). The same classifications are done for nodes along positive $y$-axis. The vertical $\left(u_{z}\right)$ displacements of nodes located from $X_{1}$ to $X_{6}, Y_{1}$ to $Y_{6}$ and $X_{7}$ to $X_{12}, Y_{7}$ to $Y_{12}$ (same inter-node distance) are recorded in time history to calculate the cone and transverse wave speeds, and the axial displacements $\left(u_{\mathrm{x}}, u_{\mathrm{y}}\right)$ of $X_{13}-X_{18} / Y_{13}-Y_{18}$ nodes for longitudinal wave speed, as shown in Figs. $7 \mathrm{c}-7 \mathrm{~h}$. The inter-node distances are divided by the associated traveling time durations of each wave to determine the average wave speed, as tabulated in Table 4. The displacements of nodes are recorded after $1.70 \mathrm{ps}$ for a suitable period in order to reflect the stress wave effects. In Figs. $7 \mathrm{c}$ and $7 \mathrm{~d}$, cone wave stops propagating at around $4.92 \mathrm{ps}$ when all nodes run along positive $z$-axis with the elastic recovery of petals. In Figs. 7e and 7f, the z-displacements of nodes in Region II grow obviously after 1.70 ps as cone wave reaches. In Figs. $7 \mathrm{~g}$ and $7 \mathrm{~h}$, the peak of nodal displacement becomes smaller due to the weakened longitudinal stress wave for interference. From snapshots (b) to (c) then to (d) in Fig. 6, we found that the initiated cracks by damage continue to propagate radially, with the extensions of cone and unloading waves, which will be further analyzed in Section 3.4 from the perspectives 
of energy changes. The crack propagation speed $C_{\mathrm{c}}$ is calculated as $0.71 C_{\mathrm{R}}$, in good agreement with the theoretical prediction of $0.73 C_{\mathrm{R}}$ (Yoffe, 1951), where the Rayleigh-wave speed $C_{\mathrm{R}}$ is approximated by (Zinin et al., 1999)

$$
C_{\mathrm{R}} \approx \frac{\left[0.72-\left(C_{\mathrm{T}} / C_{\mathrm{L}}\right)^{2}\right] \times C_{\mathrm{T}}}{\left[0.75-\left(C_{\mathrm{T}} / C_{\mathrm{L}}\right)^{2}\right]} .
$$
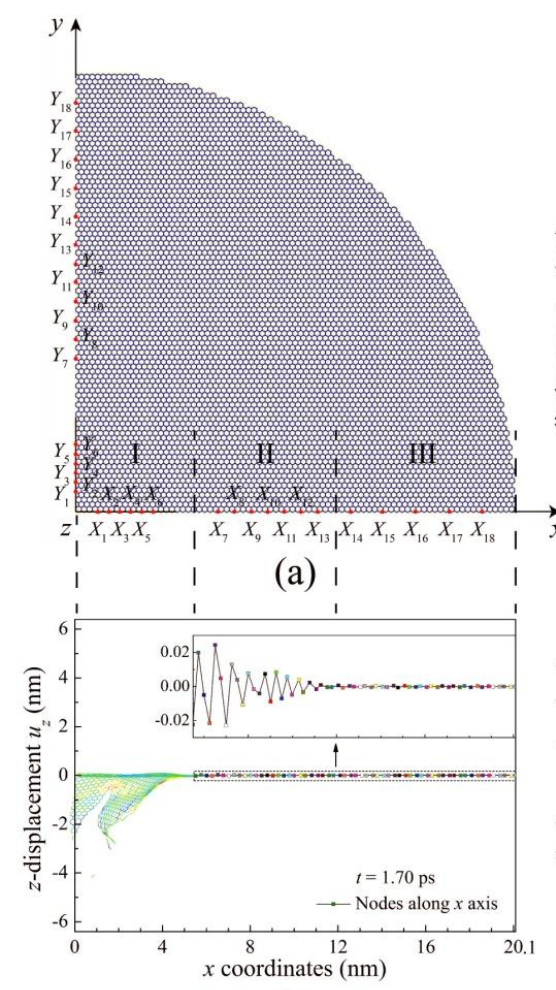

(b)

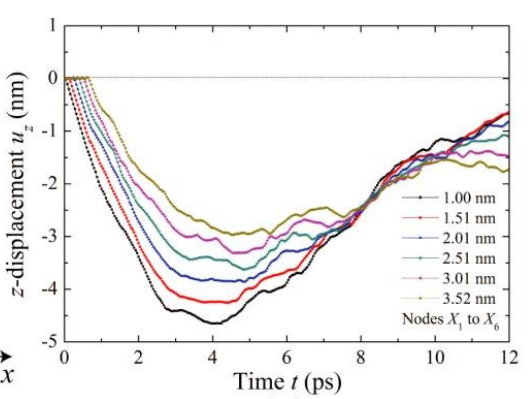

(c)

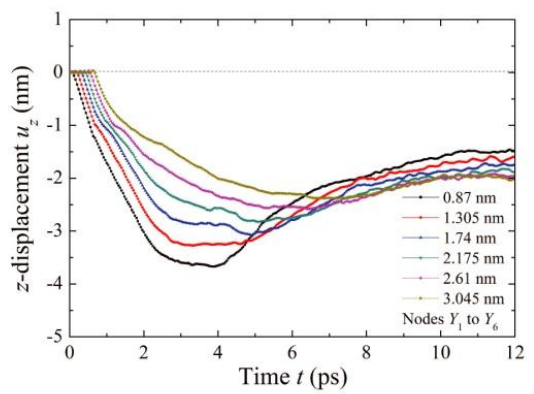

(d)

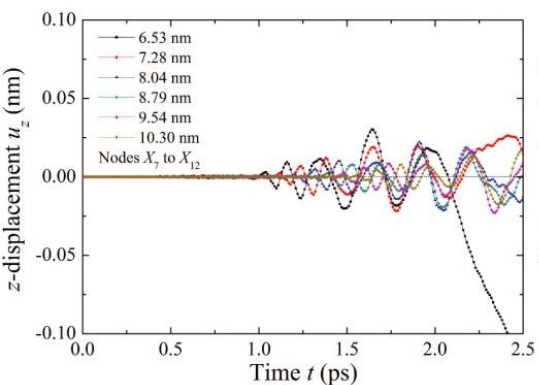

(e)

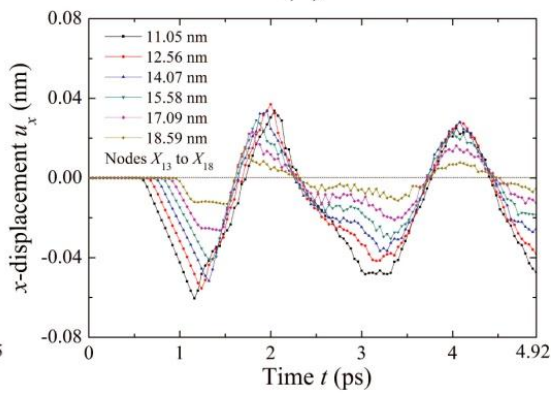

(g)

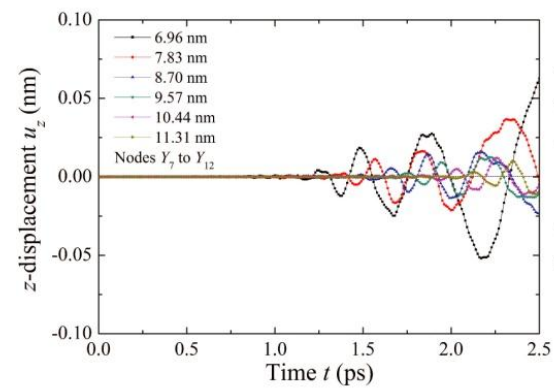

(f)

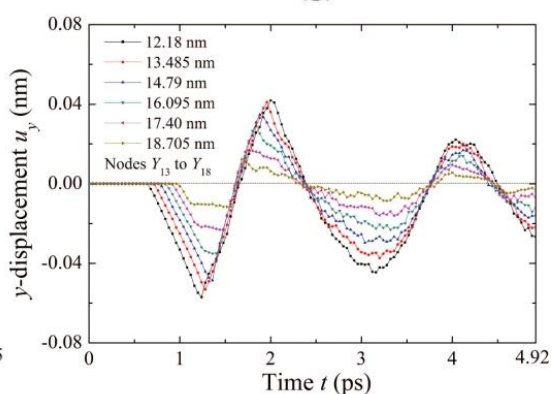

(h)

Fig. 7. (a) Top view of $1 / 4 h$-BN model with six groups of node sets labeled. (b) Transverse 
displacements of nodes (atoms) in positive $x$-axis at $1.70 \mathrm{ps}$. Time history of $z$-displacements of nodes from $X_{1}$ to $X_{6}(\mathrm{c})$, and from $Y_{1}$ to $Y_{6}$ (d) for cone wave descriptions along Zigzag and Armchair directions; (e) from $X_{7}$ to $X_{12}$, (f) from $Y_{7}$ to $Y_{12}$ for transverse wave descriptions; Time history of $x$-displacements of nodes from $X_{13}$ to $X_{18}(\mathrm{~g})$, and $y$-displacements of nodes from $Y_{13}$ to $Y_{18}$ (h) for longitudinal wave descriptions.

\section{Table 4}

Speeds of stress waves and crack propagation in $h$-BN monolayer calculated in this work, compared with theoretical values in brackets.

\begin{tabular}{llllll}
\hline Directions & $C_{\mathrm{L}}(\mathrm{km} / \mathrm{s})$ & $C_{\mathrm{T}}(\mathrm{km} / \mathrm{s})$ & $C_{\mathrm{k}}(\mathrm{km} / \mathrm{s})$ & $C_{\mathrm{R}}(\mathrm{km} / \mathrm{s})$ & $C_{\mathrm{c}}(\mathrm{km} / \mathrm{s})$ \\
\hline Zigzag & $18.84(19.08)$ & $9.42(11.61)$ & $3.95(4.68)$ & $8.85(10.69)$ & $0.71 C_{\mathrm{R}}\left(0.73 C_{\mathrm{R}}\right)$ \\
Armchair & $19.48(19.80)$ & $10.27(11.66)$ & $3.69(4.73)$ & $9.62(10.79)$ & \\
\hline
\end{tabular}

The cone wave effects on the ballistic behaviors of monolayer $h-\mathrm{BN}$ target at different impact speeds are discussed below. Once the reflected cone wave arrives at strike area, shown in snapshot Fig. 8a-iii, the reaction force reaches its maximum. If concentrated stress exceeds the critical strength of local beam (bond), bond failure occurs, leading to perforation, as shown in snapshot Fig. 8a-iv. It implies that the reflected cone wave encourages the perforation and weakens the ballistic resistance of $h$-BN monolayer. The reflected cone wave actually triggers a failure in the rebounding process although it dissipates the impact kinetic energy during the outward propagation stage (stages I and II in Fig. 5). The total time for the return of cone wave to the striking point can be estimated by

$$
t_{\mathrm{k}}=\frac{2 r}{C_{\mathrm{k}}}=\frac{2 r}{1.23 C_{\mathrm{L}}\left[V_{\mathrm{i}} /\left(\sqrt{2} C_{\mathrm{L}}\right)\right]^{2 / 3}}
$$

where target radius $r=20.1 \mathrm{~nm}$. The variation of time $t_{\mathrm{k}}$ with impact speed $V_{\mathrm{i}}$ is shown in Fig. $8 \mathrm{~b}$. The time for the appearance of the maximum reaction force at different impact speeds is also shown to Fig. 8b (FE data). Three regimes: I (rebounding), II (perforation 
with larger deformation than impact area), III (perforation within impact-area/localized deformation) are divided. The demarcations are $V_{\mathrm{bl}}(\sim 1141 \mathrm{~m} / \mathrm{s}$ by average of the highest impact speed without causing perforation and the lowest impact speed causing perforation) and $V_{\mathrm{c}}(\sim 2400 \mathrm{~m} / \mathrm{s})$, respectively, where $V_{\mathrm{c}}$ is chosen based on the failure modes of target, see details in Sections 3.4 and 3.5. The simulation results are consistent with theoretical curves in region I, and it verifies the fact that the return of the cone wave to the strike area leads to the secondary contact during rebounding (Fig. 5). At high impact speeds $\left(V_{\mathrm{i}}>V_{\mathrm{bl}}\right)$, regions II and III, the $h$-BN monolayer is perforated by projectile during the first time contact. Therefore, if a similar membrane target is designed with sufficiently large size to avoid the reflection of the cone wave, it could stop the projectiles successfully without failure. In addition, taking the longest crack's length $L_{\mathrm{m}}(\sim 5.76 \mathrm{~nm})$ in Fig. $6 \mathrm{f}$ as the maximum radius of cone, the perforation time $t_{\mathrm{p}}$ is approximated by $L_{\mathrm{m}} / C_{\mathrm{k}} \sim 1.51 \mathrm{ps}$ and the average maximum tensile strain is estimated as $\varepsilon_{\mathrm{m}} \sim\left(V_{\mathrm{i}} t_{\mathrm{p}} / L_{\mathrm{m}}\right)^{2} / 2 \sim 19.8 \%$, falling in the reported failure strain range of 5\%-25\% (Lee et al., 2014), and the average tensile strain-rate $\dot{\varepsilon}_{\mathrm{m}}=\varepsilon_{\mathrm{m}} / t_{\mathrm{p}}=\left(V_{\mathrm{i}} / L_{\mathrm{m}}\right)^{2} / 2 t_{\mathrm{p}} \sim 10^{11} \mathrm{~s}^{-1}$.

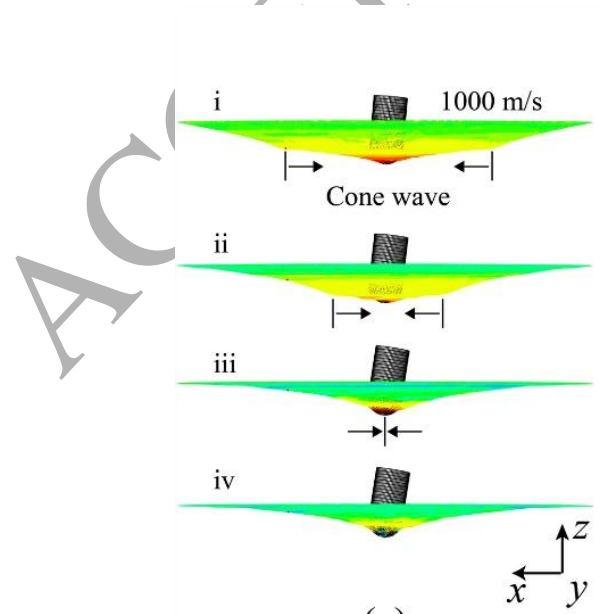

(a)

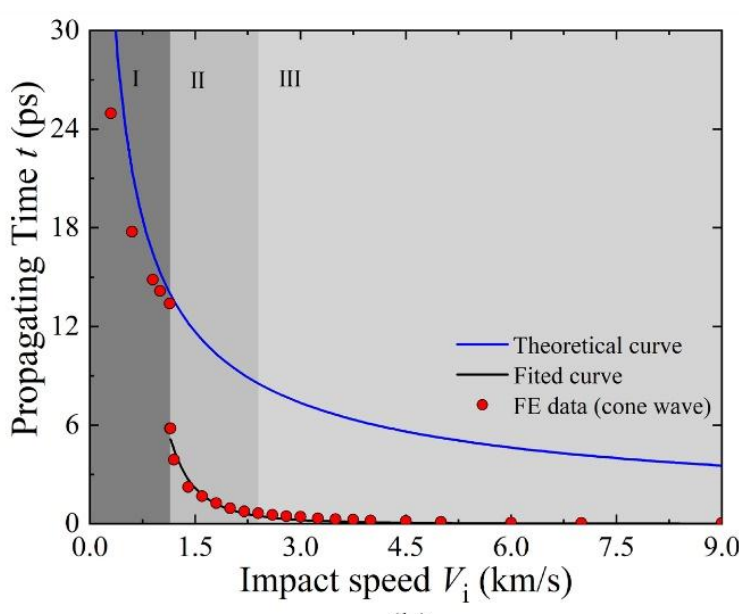

(b)

Fig. 8. (a) The propagation of a reflected cone wave: (i) at 13.08 ps when passing node A, (ii) at 14.64 ps, (iii) reaching strike area at $16.08 \mathrm{ps,} \mathrm{(iv)} \mathrm{inducing} \mathrm{perforation} \mathrm{at} 16.20 \mathrm{ps}$, in an $h$-BN monolayer at 
the impact speed of $1000 \mathrm{~m} / \mathrm{s}$; (b) The time for cone wave propagations from formation to the moment when the reaction force reaches maximum at different impact speeds, in which the large difference between theoretical and fitted curves in regions II and III indicates that the target is perforated by projectile prior to the reflection of cone wave at high impact speeds.

\subsection{Energy dissipation mechanisms of monolayer $h-B N$}

The energy absorbed by $h$-BN monolayer $\Delta E_{h \text {-BN }}$, equaling to the loss of projectile kinetic energy $-\Delta E_{\mathrm{k}}\left(\Delta E_{\mathrm{k}}<0\right)$, is composed of (a) internal energy $E_{\mathrm{i}}$, comprised by elastic strain energy $E_{\mathrm{s}}$ and damage dissipation energy, and before crack initiation only having $E_{\mathrm{s}}$, stored in the form of tensile (minor) and conic (major) deformation, (b) vibration energy $E_{\mathrm{v}}$, which is the kinetic energy of nodes (atoms) caused by stress wave propagations, (c) the energy of fragments/plug $E_{\mathrm{f}}$, including the deformation and kinetic energy of the fragments/plug, which keeps unchanged once the fragments/plug are ejected from target, and (d) damping dissipation $E_{\mathrm{d}}$, i.e.

$$
\Delta E_{h-\mathrm{BN}}=-\Delta E_{\mathrm{k}}=E_{\mathrm{i}}+E_{\mathrm{v}}+E_{\mathrm{f}}+E_{\mathrm{d}} .
$$

The damage evolutions of $h$-BN/monolayer are analyzed with the changes of energy at impact speed of $2400 \mathrm{~m} / \mathrm{s}$ in Fig. 9. The target is completely perforated at time $t_{1}$ initiating six cracks, shown by Fig. 9a-i, where the fracture energy is from the release of strain energy mainly stored in form of conic deformation around strike area before perforation, shown in Fig. 6a. From time $t_{1}$ to $t_{2}$, the cracks continue to extend, corresponding to snapshots $\mathrm{i}$ to ii (snapshot $\mathrm{f}$ in Fig. 6) in Fig. 9a, which is caused by the propagation of longitudinal tensile and cone waves, along with the increase of $E_{\mathrm{i}}$ in Fig. $9 \mathrm{~b}$. After time $t_{2}$, $E_{\mathrm{i}}$ keeps stable since the reflected compression wave cancels out tensile component to stop the spreading of the cone, meanwhile cracks stop propagating further. Then until time $t_{3}$, the vibration energy decreases as the damping dissipation increases. Finally, the $h$-BN 
monolayer reaches an equilibrium state due to the structural relaxation between time $t_{3}$ and $t_{4}$.

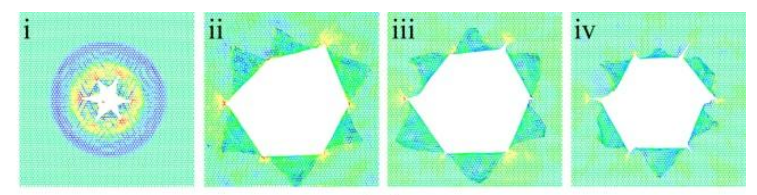

(a)

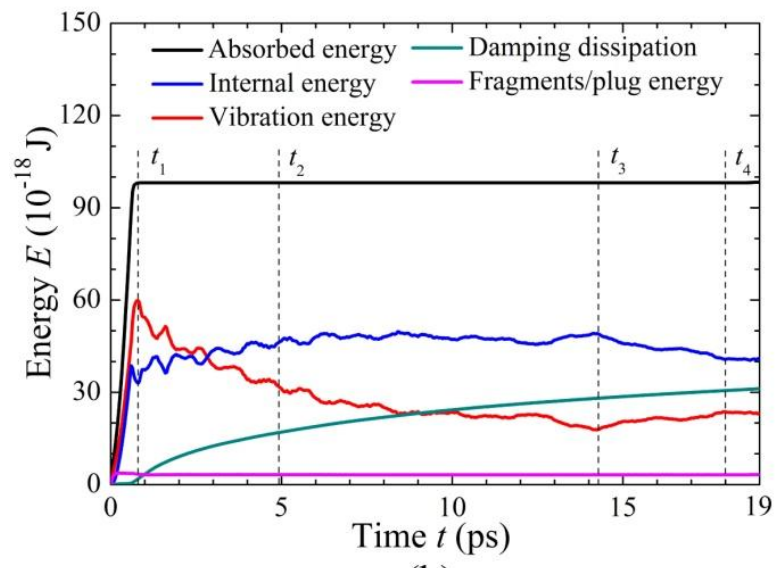

(b)

Fig. 9. (a) Damage and crack evolutions of monolayer $h$-BN during perforation at impact speed of 2400 $\mathrm{m} / \mathrm{s}$, (b) the energy-time histories (ABAQUS output), where time $t_{1}=0.6 \mathrm{ps}, t_{2}=4.92 \mathrm{ps}, t_{3}=14.68 \mathrm{ps}$, and $t_{4}=18$ ps correspond to snapshots i-iv in (a), labeled by dash lines.

The changes of energy dissipated by target from projectile against its different impact speeds are shown in Fig. 10, where the energy is calculated at the moment when projectile speed becomes zero at low impact speeds or target is completely perforated at high impact speeds. The impact energy is totally dissipated by global deformation of target as well as the vibrations (phonons) of nodes (atoms) at low impact speeds (region I), due to the efficient delocalization of stress waves. However, when $V_{\mathrm{i}}>V_{\mathrm{bl}}$ (regions II and III), the impact kinetic energy of projectile is too high to be totally absorbed by target, thus the target is perforated. The demarcation line, namely ballistic limit $V_{\mathrm{bl}}$, is determined as 1141 $\mathrm{m} / \mathrm{s}$ by Fig. 10, close to $1139 \mathrm{~m} / \mathrm{s}$ calculated according to Eq. (7), i.e. when $V_{\mathrm{r}}=0$, then $V_{\mathrm{bl}}$ $=V_{\mathrm{i}}$, and in this case, the absorbed energy can be expressed by $\mathrm{m}_{\mathrm{p}}\left(V_{\mathrm{bl}}\right)^{2} / 2$. At higher 
impact speeds (region III), the internal energy is almost unchanged as damage occurs nearly within the strike area. The fragments are ejected with higher speeds, leading to much greater kinetic energy.

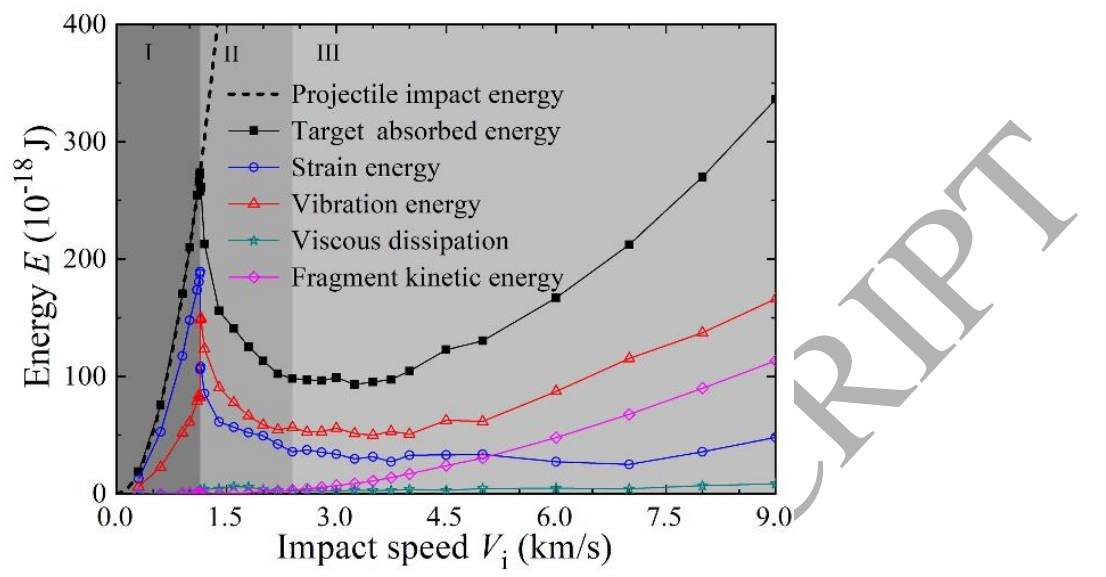

Fig. 10. The initial kinetic energy of nano-projectile (expressed by $E_{\mathrm{p}}^{\mathrm{i}}=m_{\mathrm{p}} V_{\mathrm{i}}^{2} / 2$, as portrayed by dash line) absorbed totally by monolayer $h$-BN at low impact speed $\left(E_{\mathrm{p}}^{\mathrm{i}}=\Delta E_{h \text {-BN }}\right.$ in region I), but absorbed partially by monolayer at high impact speed ( $E_{\mathrm{p}}^{\mathrm{i}} \gg \Delta E_{h-\mathrm{BN}}$ in regions II and III), together with the kinetic energy loss of projectile, which is absorbed by target (solid line with solid dots) in four forms (solid lines with hollow dots).

The total energy absorbed by monolayer $h$-BN before and after penetration, termed as the penetration energy $E_{\mathrm{p}}$ (Lee et al.,2014) equals to the value of $\Delta E_{h \text {-BN }}$ when perforation occurs. Based on (Lee et al., 2014), it is adjusted and expressed by $E_{\mathrm{p}}=\left(\rho^{2 \mathrm{D}} A_{\mathrm{s}}\right) V_{\mathrm{i}}^{2} / 2+U_{\mathrm{m}} A_{\mathrm{s}}+E_{\mathrm{d}}$ in this work, where the first term represents the kinetic energy transferred to target within $A_{\mathrm{s}}$, the second represents the strain energy within $A_{\mathrm{s}}$ for crack initiation, and $E_{\mathrm{d}}$ is the energy dissipated by other mechanisms, thus the specific penetration energy $E_{\mathrm{p}}^{*}=E_{\mathrm{p}} / \rho^{2 \mathrm{D}} A_{\mathrm{s}}=\left(V_{\mathrm{i}}^{2} / 2+\bar{U}_{\mathrm{m}}\right)+E_{\mathrm{d}}^{*}$ where $E_{\mathrm{d}}^{*}$ is the delocalized energy by the outward propagation of stress waves, as compared with the local dissipation term $V_{\mathrm{i}}^{2} / 2+\bar{U}_{\mathrm{m}}$ in Fig. 11. We found that, with the increase of impact speed, the kinetic energy of projectile is increasingly absorbed by the local deformation and damage of target, and 
especially for $V_{\mathrm{i}} \geq 4.0 \mathrm{~km} / \mathrm{s}$, it dominates the energy dissipation.

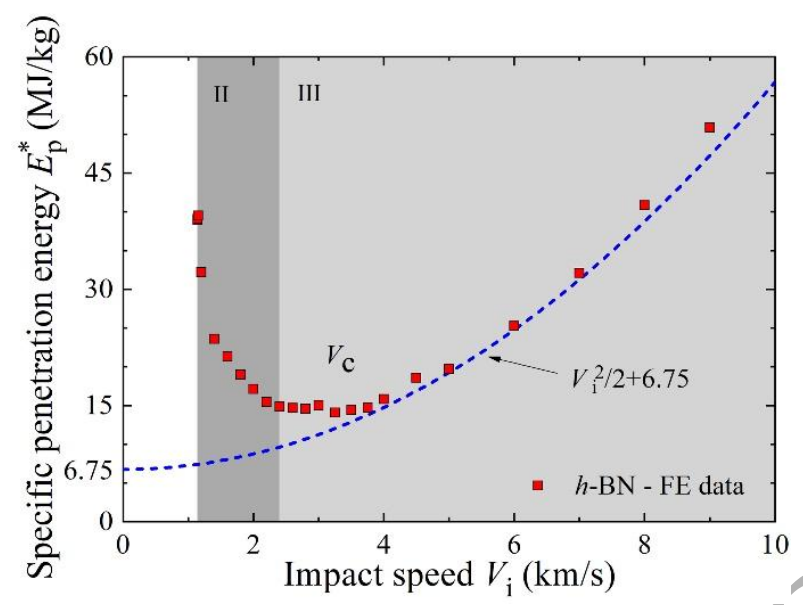

Fig. 11. Specific penetration energy of monolayer $h-\mathrm{BN}$ at different impact speeds

\subsection{Failure characteristics of monolayer $h-B N$}

Four failure modes of $h$-BN target are revealed at representative impact speeds in Fig. 12a, i.e. (a) failure with bulge on the upper surface of target and petals opposite the impact direction when $V_{\mathrm{i}}<V_{\mathrm{bl}}$ (perforation during, rebounding), shown by snapshot i. (b) Failure of dishing and disking on the lower surface of target when $V_{\mathrm{bl}}<V_{\mathrm{i}}<V_{\mathrm{c}}$, shown by snapshots ii and iii. It is related to the bulging, deflection and tensile tearing of target. (c) Petalling-type failure with little or no dishing when $V_{\mathrm{c}} \leq V_{\mathrm{i}}<4.0 \mathrm{~km} / \mathrm{s}$, shown by snapshot iv. (d) Plugging failure when $V_{\mathrm{i}} \geq 4.0 \mathrm{~km} / \mathrm{s}$, characterized by the ejection of a plug with a diameter similar to that of projectile (or in the form of fragments), shown by snapshots $\mathrm{v}$ and vi. According to Fig. 12b, more radial cracks, petals and larger debris but shorter final radius of cone are associated with the increase of impact speed, and the failure area is increasingly localized. The angle between the adjacent cracks (apex angle, $\theta$ ) along the zigzag direction is approximately the multiplication of $30^{\circ}$ (Lee et al., 2014). At impact speed above $2.4 \mathrm{~km} / \mathrm{s}$, the energy for the creation of new surfaces (crack initiation) is provided by the elastic energy of the local conic bulge in target before perforation. Thus, 
the maximum number of cracks $n_{\mathrm{m}}$ can be estimated by

$$
n_{\mathrm{m}}=\left\lfloor\frac{U_{\mathrm{m}} A_{\mathrm{s}}}{2 \gamma r_{\mathrm{p}} h_{\mathrm{t}}}\right\rfloor,
$$

where $\lfloor x\rfloor$ is the floor function of the real number $x$ (output the greatest integer less than or equal to $x$ ); $\gamma$ is the edge energy of $h$-BN for zigzag edge, taken as $6.01 \mathrm{~J} / \mathrm{m}^{2}$ by ref. (Wei et al., 2015). The stored strain energy is primarily for crack initiation, but released partly by target's relaxation to generate compression wave along with node vibrations, as shown in Fig. 6 and Fig. 9. The crack numbers versus impact speeds from FE simulations are portrayed in Fig. 13, and six seems the upper bound of cracks, consistent with the predicted crack number. Moreover, we found that the initiated cracks prefer to propagate along a zigzag direction, and the identical fracture feature is observed by Tabarraei and Wang (2015) in $h$-BN monolayer under mixed mode I and mode II loading. Thus schematic in Fig. 12c gives the preferential propagation paths of cracks based on the hexagonal-cell structure of $h$-BN monolayer. It predicts the most possible crack paths in atomistic-scale successfully, as shown in Fig. 12b and (Haque et al., 2016), that the maximum crack number is six and the apex angle of petalling is around $60^{\circ}$ (the strike point is the apex point). If zigzag crack kinks during its growth, crack would deviate to an armchair direction and propagate along a short path, then deviates to a new zigzag direction to propagate (Tabarraei and Wang, 2015), which leads to the formation of angle of nearly $30^{\circ}$ in Fig. $12 \mathrm{~b}$. We also found that the fracture area is local and has 3-6 cracks at low impact speeds. Our researches could give reasonable explanations for the microscopic (Lee et al., 2014) and macroscopic fracture properties of $h$-BN and other 2D crystal materials to guide their applications in structure design of composite armor. 


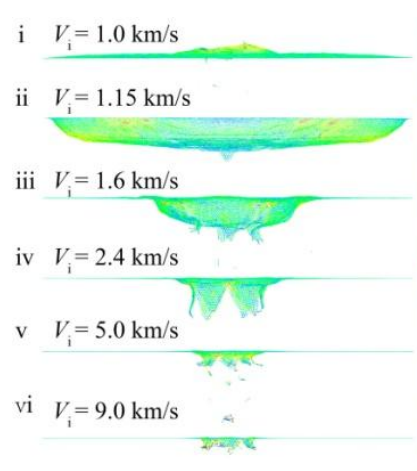

(a)

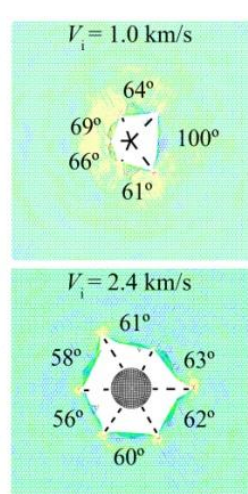

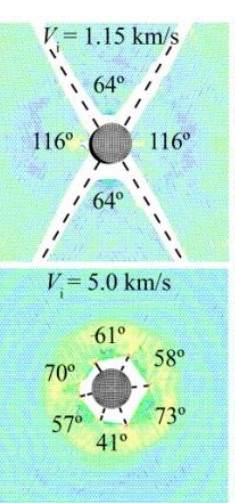

(b)

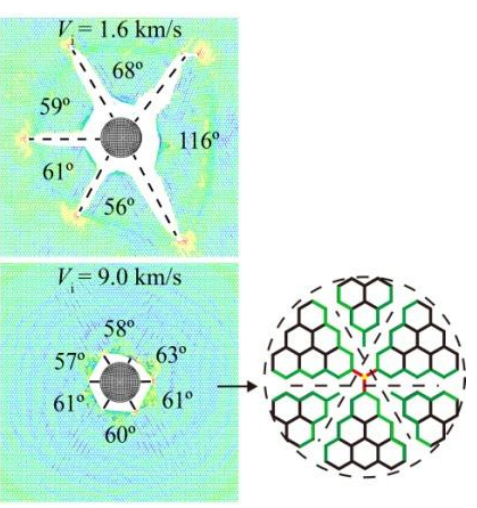

(c)

Fig. 12. Representative failure patterns of $h$-BN monolayer perforated by a nano-projectile at impact speeds of $1.0 \mathrm{~km} / \mathrm{s}, 1.15 \mathrm{~km} / \mathrm{s}, 1.6 \mathrm{~km} / \mathrm{s}, 2.4 \mathrm{~km} / \mathrm{s}, 5.0 \mathrm{~km} / \mathrm{s}$ and $9.0 \mathrm{~km} / \mathrm{s}$ : (a) Side views ( $x-z$ plane); (b) Top views ( $x-y$ plane), snapshotting when cracks reach the limit without further extension; (c) Schematic illustration depicts the preferential paths for crack initiation and evolution, marked by the dash straight lines, where yellow point is the striking point, red lines represent the breakage beams (bonds) subjected to the concentrated load (crack initiation) and green tines outline the newly created zigzag edges.

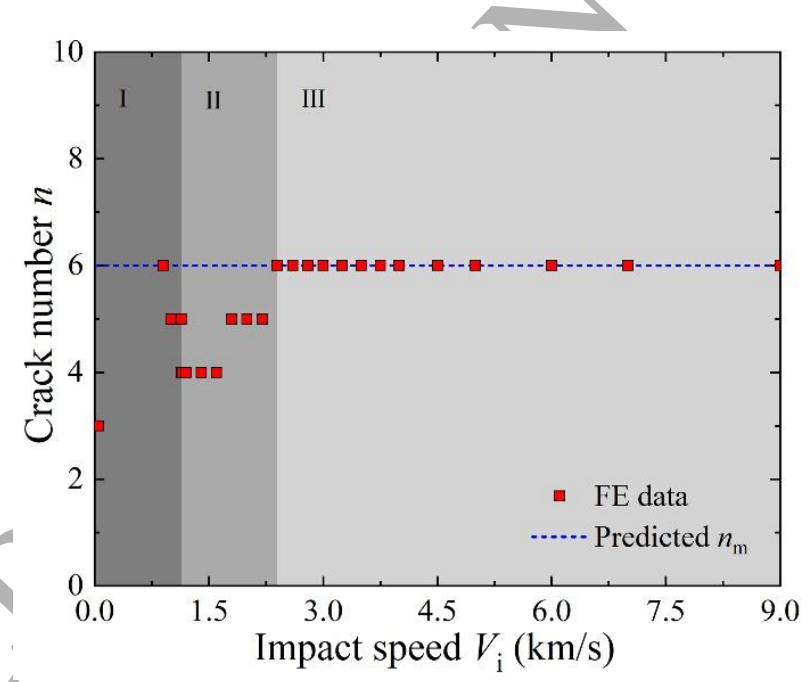

Fig. 13. Relationship between the crack numbers and impact speeds, where the crack number is 3 at indentation speed of $0.05 \mathrm{~km} / \mathrm{s}$, obtained by nano-indentation simulation in Section 2.2 .

\section{Conclusions}

Ballistic tests of monolayer $h$-BN target under the transverse impact of nano-projectile are simulated by an explicit FE method, wherein the equivalent structural model is constructed using B31 elements with B-N bonds implemented. The impact responses of $h$-BN layer are analyzed under various loading conditions. At low impact speeds, we focus 
on the second impact of projectile occurring in the rebounding process. At high impact speeds, we reveal the linkage among the fracture patterns of target (cracks), the dissipated energy and the propagations of stress waves (mainly cone wave) during perforation. The high wave and crack propagation speeds make that $h$-BN is superior for impact resistance over the traditional armor materials. The ballistic limit $V_{\mathrm{bl}}$ of monolayer $h-\mathrm{BN}$ is determined as $1141 \mathrm{~m} / \mathrm{s}$, nearly 10 times of Kevlar 129's ballistic limit under the same areal density. Therefore, $h$-BN is a promising material candidate for advanced composite armors.

Further work to investigate the influences of other parameters, e.g. projectile deformability, boundary condition, impact oblique angle etc., on the ballistic resistance of $h$-BN monolayer is still ongoing.

\section{Acknowledgements}

This work is partially supported by NSFC (11872202), Natural Science Foundation of Jiangsu Province (BK20161483), Aeronautical Science Foundation (2016ZF52063), “Qin Lan Project" of Jiangsu province, Foundations of State Key Laboratory of Mechanics and Control of Mechanical Structures (NUAA, No. MCMS-0216G01; MCMS-0217K01).

\section{References}

Acar, A., Colak, O., Correia, J.P.M., Ahzi, S., 2018. Cooperative-VBO model for Polymer/Graphene Nanocomposites. Mech. Mater. 125, 1-3.

Al-Jishi, R., Dresselhaus, G., 1982. Lattice-dynamical model for graphite. Phys. Rev. B: Condens. Matter 26, 4514-4522.

Baykasoglu, C., Mugan, A., 2012. Nonlinear fracture analysis of single-layer graphene sheets. Eng. Fract. Mech. 96, 241-250.

Bhatia, N.M., Nachbar, W., 1968. Finite indentation of an elastic membrane by a spherical 
indenter. Int. J. Nonlinear Mech. 3, 307-324.

Boldrin, L., Scarpa, F., Chowdhury, R., Adhikari, S., 2011. Effective mechanical properties of hexagonal boron nitride nanosheets. Nanotechnology 22, 505702.

Bosak, A., Serrano, J., Krisch, M., Watanabe, K., Taniguchi, T., Kanda, H., 2006. Elasticity of hexagonal boron nitride: Inelastic x-ray scattering measurements. Phys. Rev. B 73, 041402.

Brenner, D.W., 1990. Empirical potential for hydrocarbons for use in simulating the chemical vapor deposition of diamond films. Phys. Rev. B 42, 9458-9471.

Cunniff, P.M., 1999. Dimensionless parameters for optimization of textile based body armor systems. Proc. 18th Int. Symp. of Ballistics, San Antonio, TX, November 15-19, p. 1303-1310.

Geim, A.K., Grigorieva, I.V., 2013. Van der Waals heterostructures. Nature 499 (7459), 419-425.

Gotsmann, B., Rothuizen, H., Duerig, U., 2008. Ballistic nanoindentation of polymers. Appl. Phys. Lett. 93 (9), 39.

Griffith, A.A., 1921. The phenomena of rupture and flow in solids. Philos. Trans. R. Soc. London 221 (2), 163-198.

Hadi, M.S., Shokrieh, M.M, 2018. Strength calculation of graphene/polymer nanocomposites using the combined laminate analogy and progressive damage model. Mech. Mater. 127, 48-54.

Han, T., Luo, Y., Wang, C., 2014. Effects of temperature and strain rate on the mechanical properties of hexagonal boron nitride nanosheets. J. Phys. D: Appl. Phys. 47 (2), $25303-25310$.

Haque, B.Z.(G.), Chowdhury, S.C., Gillespie Jr., J.W., 2016. Molecular simulations of stress wave propagation and perforation of graphene sheets under transverse impact. Carbon 102, 126-140.

Haubner, R., Wilhelm, M., Weissenbacher, R., Lux, B., 2002. Boron Nitrides-Properties, Synthesis and Applications. Springer Berlin Heidelberg: Berlin, Heidelberg, Germany, $6(9), 1539-1553$. 
Hibbit, K.A.S., 2009. ABAQUS Theory and User Manuals Version 6.9. USA: ABAQUS Inc.

Komaragiri, U., Begley, M.R., Simmonds, J.G., 2005. The mechanical response of freestanding circular elastic films under point and pressure loads, J. Appl. Mech. 72, 203-212.

Kubota, Y., Watanabe, K., Tsuda, O., Taniguchi, T., 2007. Deep ultraviolet light-emitting hexagonal boron nitride synthesized at atmospheric pressure. Science 317 (5840), 932-934.

Kumar, R., Rajasekaran, G., Parashar, A., 2016. Optimised cut-off function for Tersoff-like potentials for a BN nanosheet: a molecular dynamics study. Nanotechnology 27 (8), 085706.

Lambert, J.P., Jonas, G.H., 1976. Towards Standardization in Terminal Ballistics Testing: Velocity Representation. BRL Report No. 1852, Aberdeen Proving Ground, MD: U.S. Army Ballistic Research Laboratories, p. 51.

Lee, C., Wei, X., Kysar, J.W., Hone, J., 2008. Measurement of the Elastic Properties and Intrinsic Strength of Monolayer Graphene. Science 321 (5887), 385-388.

Lee, J.H., Loya, P.E., Lou, J., Thomas, E.L., 2014. Dynamic mechanical behavior of multilayer graphene via supersonic projectile penetration. Science 346, 1092-1096.

Lee, Y.H., Zhang, X.Q., Zhăng, W., Chang, M.T., Lin, C.T., Chang, K.D. et al., 2012. Synthesis of large-area MoS2 atomic layers with chemical vapor deposition. Adv. Mater. 24 (17), 2320-2325.

Li, C., Chou, T.-W., 2003. A structural mechanics approach for the analysis of carbon nanotubes. Int. J. Solids Struct. 40, 2487-2499.

Lim, C.T., Shim, V.P.W., Ng, Y.H., 2003. Finite-element modeling of the ballistic impact of fabric armor. Int. J. Impact Eng. 28, 13-31.

Lu, G., Wu, T., Yuan, Q., Wang, H.S., Wang, H.M., Ding, F., Xie, X., Jiang, M., 2015. Synthesis of large single-crystal hexagonal boron nitride grains on $\mathrm{Cu}-\mathrm{Ni}$ alloy. Nat. Commun. 6, 6160.

Oh, E.S., 2010. Elastic properties of boron-nitride nanotubes through the continuum lattice 
approach. Mater. Lett. 64, 859-862.

Partoens, B., Peeters, F.M., 2006. From graphene to graphite: Electronic structure around the K point. Phys. Rev. B 74 (7), 075404.

Peng, Q., Ji, W., De, S., 2012. Mechanical properties of the hexagonal boron nitride monolayer: Ab initio study. Comput. Mater. Sci. 56, 11-17.

Phoenix, S.L., Porwal, P.K., 2003. A new membrane model for the ballistic impact response and V50 performance of multi-ply fibrous systems. Int. J. Solids Struct. 40, 6723-6765.

Plimpton, S., 1995. Fast parallel algorithms for short-range molecular dynamics. J. Comput. Phys. 117, 1-19.

Rubio, A., Corkill, J.L., Cohen, M.L., 1994. Theory of graphitic boron nitride nanotubes. Phys. Rev. B: Condens. Matter 49, 5081-5084.

Scarpa, F., Adhikari, S., 2008. A mechanical equivalence for Poisson's ratio and thickness of C C bonds in single wall carbon nanotubes. J. Phys. D: Appl. Phys. 41 (8), 085306.

Shokrieh, Z., Seifi, M., Shokrieh, M.M., 2017. Simulation of stiffness of randomly-distributed-graphene/epoxy nanocomposites using a combined finite element-micromechanics method. Mech. Mater. 115, 16-21.

Tabarraei, A., Wang, X., 2015. A molecular dynamics study of nanofracture in monolayer boron nitride. Mater. Sci. Eng. A 641, 225-230.

Tan, X., Wu, J., Zhang, K., Peng, X., Sun, L., Zhong, J., 2013. Nanoindentation models and Young's modulus of monolayer graphene: A molecular dynamics study. Appl. Phys. Lett. 102 (7), 109.

Tersoff, J., 1988. New empirical approach for the structure and energy of covalent systems. Phys. Rev. B 37, 6991-7000.

Tian, H., Yang, X.J., Yang, G., Zhang, B., 2018. Instability of rapidly accelerating rupture fronts in nanostrips of monolayer hexagonal boron nitride. Eng. Fract. Mech. 200, 115-124.

Tserpes, K.I., Papanikos, P., Tsirkas, S.A., 2006. A progressive fracture model for carbon nanotubes. Compos. Part B: Eng. 37, 662-669.

Wang, W., Shuai, L., Min, J., Yi, C., Zhan, Y., Li, M., 2014. Nanoindentation experiments 
for single-layer rectangular graphene films: a molecular dynamics study. Nanoscale Res. Lett. 9 (1), 1-8.

Wan, K.-T., Guo, S., Dillard, D.A., 2003. A theoretical and numerical study of a thin clamped circular film under an external load in the presence of a tensile residual stress. Thin Solid Films 425, 150-162.

Wei, X., Xiao, S., Li, F., Tang, D., Chen, Q., Bando, Y. et al., 2015. Comparative Fracture Toughness of Multilayer Graphenes and Boronitrenes. Nano Lett. 15 (1), 689-694.

Wetzel, E.D., Balu, R., Beaudet, T.D., 2015. A theoretical consideration of the ballistic response of continuous graphene membranes. J. Mech. Phys. Solids 82, 23-31.

Wu, J., Wang, B., Wei, Y., Yang, R., Dresselhaus, M., 2013. Mechanics and Mechanically Tunable Band Gap in Single-Layer Hexagonal Boron-Nitride. Mater. Res. Lett. 1, 200-206.

Yoffe, E.H., 1951. The moving Griffith crack. Philos. Mag. 42, 739-750.

Yoon, K., Ostadhossein, A., Duin, A.C.T.V., 2016. Atomistic-scale simulations of the chemomechanical behavior of graphene under nanoprojectile impact. Carbon 99, $58-64$.

Zhang, B., Xiao, H., Yang, G., Liu, X., 2015. Finite element modelling of the instability in rapid fracture of graphene. Eng. Fract. Mech. 141, 111-119.

Zhang, G., Zhang, X.W., 2015. Strain effects on thermoelectric properties of two-dimensional materials. Mech. Mater., 91, 382-398.

Zinin, P., Lefeuvre, O., Briggs, A., Zeller, B.D., Cawley, P., Kinloch, A. et al., 1999. Determination of density and elastic constants of a thin phosphoric acid-anodized oxide film by acoustic microscopy. J. Acoust. Soc. Am. 106, 2560-2567. 


\section{GRAPHICAL ABSTRACT}

(a)

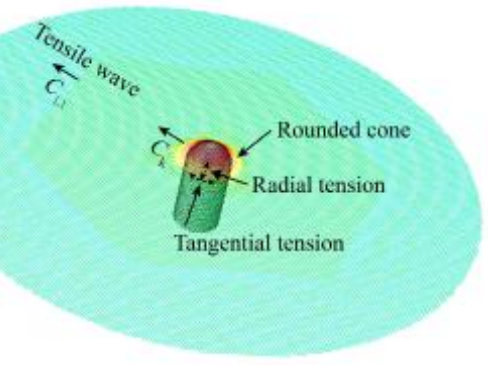

(c)

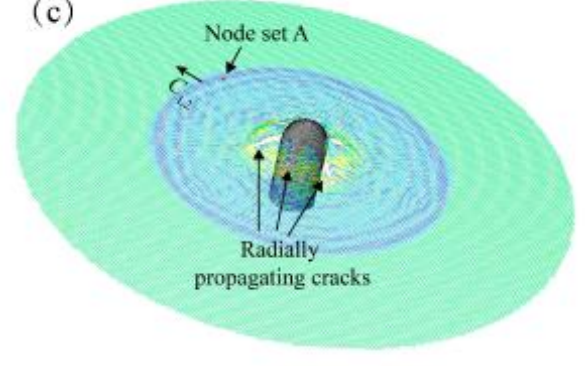

(e)

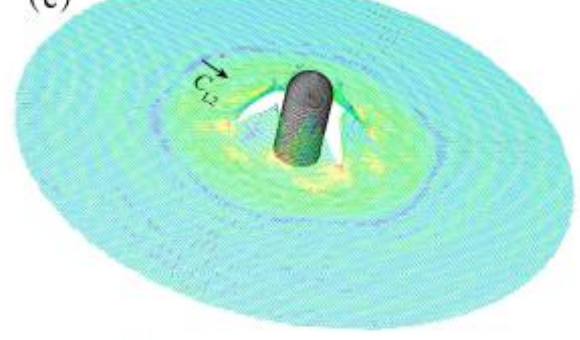

(b)

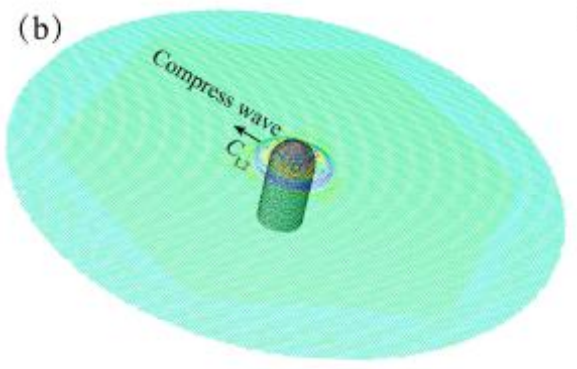

(d)

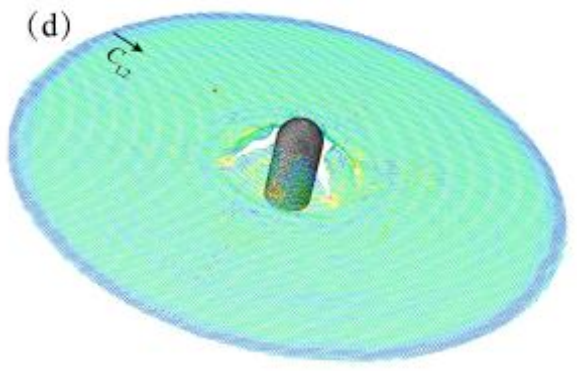

(f)

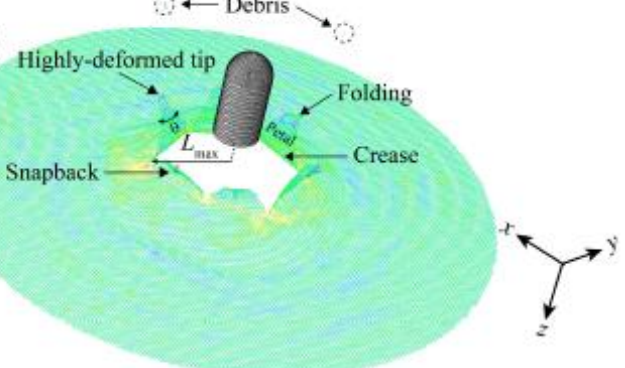

Series of dynamic events at impact speed of $2400 \mathrm{~m} / \mathrm{s}$. Snapshots (an oblique view from the bottom side) of (a) cone wave propagation at time $0.58 \mathrm{ps}$; (b) unloading (compression) wave formation at $0.76 \mathrm{ps}$; (c) the moment when the unloading wave passes node A at $1.12 \mathrm{ps}$; (d) reflection at fixed boundary at $1.70 \mathrm{ps}$; (e) the moment when the reflected unloading wave re-passes node $A$ at 2.14 ps, and (f) the perforated target at 4.92 ps.

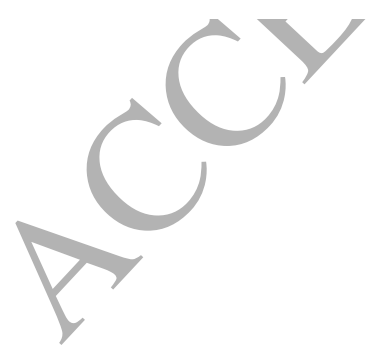

